Research Article

\title{
Theoretical Analysis and Experimental Evaluation of Road Dynamic Behavior on Different Subgrades
}

\author{
Xiaoxia Zhao, ${ }^{1}$ Jun Wang, ${ }^{1,2}$ and Guangya Ding $\mathbb{D}^{1,2}$ \\ ${ }^{1}$ College of Architecture and Civil Engineering, Wenzhou University, Wenzhou 325035, China \\ ${ }^{2}$ The Key Laboratory of Engineering and Technology for Soft Soil Foundation and Tideland Reclamation of Zhejiang Province, \\ Wenzhou University, Wenzhou 325035, China
}

Correspondence should be addressed to Guangya Ding; guangyading@hotmail.com

Received 17 January 2019; Accepted 4 April 2019; Published 30 April 2019

Academic Editor: Evangelos J. Sapountzakis

Copyright (c) 2019 Xiaoxia Zhao et al. This is an open access article distributed under the Creative Commons Attribution License, which permits unrestricted use, distribution, and reproduction in any medium, provided the original work is properly cited.

\begin{abstract}
The dynamic characteristics of a road on a subgrade filled with different materials under traffic loads are studied. An elastic double-layer plate model on a viscoelastic subgrade is established to describe the dynamic behavior of the road. The load diffusion path in the form of a cone in the stabilised layer under single vibration source and three vibration sources is considered, and the equations for the displacement and effective soil pressure of the elastic double-layer plate on the viscoelastic subgrade are derived. The relevant empirical formulae are then properly revised to reflect the dynamic behavior of the road. The dynamic response of the road is analysed by adjusting factors such as the excitation load, excitation frequency, and subgrade filling materials. The results show that gravel as a subgrade filling material has a better vibration reduction effect than sand bag. In addition, the test data not only have good consistency with the theoretical formulae but also validate the reliability of the empirical formulae.
\end{abstract}

\section{Introduction}

The dynamic responses of a road subjected to traffic loads have been widely studied in civil engineering. Most of the world's highways are paved using an asphalt layer, which is normally laid on a subgrade consisting of two or more layers of different materials. The movement of vehicles over the pavement may cause vibration and deformation in the subgrade, requiring high-cost maintenance and reducing the service life of highways. Thus, it is important to accurately predict the dynamic response of highway structures considering the vehicle-pavement interaction. Numerous numerical simulations and testing models have been proposed to predict the dynamic responses of highway pavement and subgrade.

Several simple discrete element models have been widely applied to investigate the effects of vehicle vibration on roads. Oscarsson and Dahlberg [1] developed a simplified numerical method to study the vertical dynamic characteristics of a railway track under moving loads. Kouroussis et al. [2] proposed a coupled lumped mass (CLM) model to study the dynamic interaction between a track and a soil. Zhai and Cai [3] developed a numerical model to simulate the dynamic response between a train and a railway track. Although these models do not accurately reflect the dynamic response of a highway structure, simple discrete models are acceptable for solving practical engineering problems.

Compared to the discrete element models, the viscoelastic models are more reasonable for the dynamic response analysis of highways or railway structures. Generally, an elastic structure is filled in layers such that the elastic model can more effectively reflect the characteristics of the structure, and analytical methods can be used to obtain the dynamic response of layered elastic structures. For example, Lu et al. [4] used the reflection matrix (TRM) method to study the dynamic characteristics of a layered road-subgrade system. The results showed that the TRM could effectively predict the stress and multilevel elastic deformation of the road structure. Lih and Mal [5] developed a multiple transformation technique to obtain double integral expressions for the displacement and stress in a composite laminate under dynamic loading. They found that this 
technique can more effectively determine the wave field in the laminate. Sheng et al. [6, 7] established a series of parallel viscoelastic layers with an elastic half space or a rigid foundation to discuss the characteristics of vibration generated by the load. Karlström and Boström [8] used Fourier series to build a layered half-space model of a linear viscoelastic layer, and Karlström [9] compared the train speed with the corresponding constant speed. In addition, many methods have been used to conduct the dynamic analysis of layered viscoelastic media, such as finite element method (FEM) (Mulungye et al. [10]; Kim and Tutumluer [11]; Younesian and Sadri [12]; and Connolly et al. [13]), moving element method (MEM) (Koh et al. [14]), and boundary element method (BEM) (Rasmussen et al. [15]).

Because of the complexity of road structure layers, when analysing the dynamic response of the road structure, the vehicle load is generally simplified as a static load or as a harmonic load, and the surface layer is simplified as a thin plate or as a beam on a viscoelastic subgrade (Winkler or Kelvin). Kim and Roesset [16], Kim and McCullough [17], and Kim [18] studied the dynamic response of an infinitely large Kirchhoff plate on a viscoelastic foundation under harmonic loads. The results showed that, when considering viscosity of foundation, there were significant differences from those obtained with an elastic system. Sun [19-21] employed integral transformation and Green's function to derive the dynamic displacements of beams and plates under moving loads. The maximum displacement response was found to occur at the centre of the moving load, and the propagation speed was the same as that of the moving load. Kargarnovin and Younesian [22] and Kargarnovin et al. [23] investigated the dynamic response of an infinitely long Timoshenko beam on a foundation (Pasternak) subjected to a simple harmonic load. It was found that the load distribution shape, load velocity, and frequency significantly affected the dynamic response of the beam. Huang and Thambiratnam [24] studied the dynamic response of a moving acceleration point load and discussed the influence of the initial moving speed, acceleration, and initial load position on the dynamic response. In another study [25], they further discussed the dynamic response of plate structures on elastic foundations under different moving loads. The results showed that the foundation stiffness and the speed and frequency of moving loads have a significant effect on the dynamic response and resonance speed of the plate. Lu et al. [26] and $\mathrm{Lu}$ and Yao [27] investigated the dynamic displacement response of a continuousreinforced concrete pavement (CRCP) on a viscoelastic subgrade under harmonic moving loads. Zibdeh and AbuHilal [28] discussed the random dynamic response of composite coated beams under random moving loads. It was found that the speed, blade thickness, and coating direction significantly affect the vibration response of the beam.

Most concrete tests have been conducted to describe the dynamic response of rail traffic under dynamic loads. Nimbalkar and Indraratna [29] improved the performance of geosynthetics and rubber shockmat as the buffer layer on different subgrades under the action of rail traffic. Liu et al.
[30] studied the vibration reduction effect of a soilbag under dynamic loads. The results showed that the vertical and horizontal vibrations can be effectively reduced using the soilbag. Shaer et al. [31] simulated the settlement and dynamic behavior of a ballasted railway track under high-speed train load. It was found that the stiffness of the track can undergo significant variations during the experiment, and the settlement function for the acceleration of sleepers was also analysed. However, the dynamic response characteristics of road filling materials under vehicle loading conditions have not been clearly understood.

In this study, an elastic double-layer plate model on a viscoelastic subgrade is used to analyse the dynamic response of a road under the action of dynamic loads. An asphalt layer and a stabilised layer (cement stabilised gravel with $10 \%$ content) are considered as elastic support plates. By simplifying the vibration differential equation used for the elastic double-layer plate and using the Fourier transform and trigonometric series, the vertical displacement expression for the double plate on the viscoelastic subgrade is obtained. In addition, the load diffusion path in the form of a cone in the stabilised layer under the conditions of single vibration source and three vibration sources is considered, and its effect on the stiffness of the structural layer is analysed. Moreover, the test data were used to verify the rationality and stability of other empirical formulae.

\section{Elastic Double-Layer Plate Model on Viscoelastic Subgrade}

The Kirchhoff plate assumption is stable and reliable only if the thickness-to-width ratio of a plate is lower than 0.05 . Based on the single-layer plate model [32], an elastic doublelayer plate model on a viscoelastic subgrade is assumed, as shown in Figure 1. The thicknesses of the asphalt and stabilised layers are low compared to their length and width. Therefore, the behavior can be described using an elastic double-layer plate with a width $2 b=0.8 \mathrm{~m}$. An orthogonal $X$ $Y-Z$ coordinate system is set up at the pavement layer. The load acting on the surface of the asphalt layer is $F(x, y, t)$ and the circular load with $d_{1}=0.15 \mathrm{~m}$.

As shown in Figure 1, the established model consists of an upper plate to account for the asphalt layer (with mass density $M_{1}$ per unit area and flexural rigidity $D_{1}$ ) and a lower plate to account for the stabilised layer (with mass density $M_{2}$ per unit area and flexural rigidity $\left.D_{2}\right)$. The flexural rigidity $D$ is given by $E h^{3} / 12\left(1-\mu^{2}\right)$, where $E$ is the resilient modulus, $h$ is the thickness of the plate, and $\mu$ is Poisson's ratio. The asphalt layer is supported by a continuous layer with stiffness $K_{1}$ and damping constant $C_{1}$ per unit area. The stabilised layer is supported by a continuous layer with stiffness $K_{2}$ and damping constant $C_{2}$ per unit area. The subgrade is supported with stiffness $K_{3}$ and damping constant $C_{3}$ per unit area. For a single-layer plate model resting on a Winkler foundation, the vibration differential equation for the elastic double plate on the viscoelastic subgrade can be simplified as follows: 


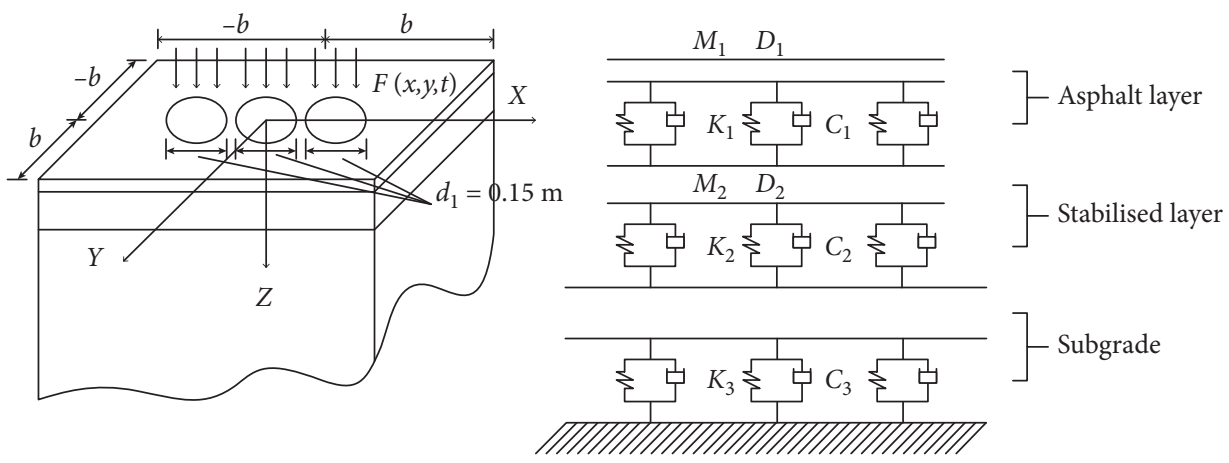

FigURE 1: Elastic double-layer plate model on a viscoelastic subgrade.

$$
\begin{aligned}
& D\left[\frac{\partial^{2} Z(x, y, t)}{\partial x^{2}}+2 \frac{\partial^{2} Z(x, y, t)}{\partial x \partial y}+\frac{\partial^{2} Z(x, y, t)}{\partial y^{2}}\right] \\
& \quad+M \frac{\partial^{2} Z(x, y, t)}{\partial t^{2}}-K Z(x, y, t)-C Z(x, y, t)=F(x, y, t),
\end{aligned}
$$

where $D=D_{1}+D_{2}, M=M_{1}+M_{2}, K=K_{1}+K_{2}+K_{3}$, and $C=C_{1}+C_{2}+C_{3}$.

According to Liu et al. [33], when $y= \pm b$, the boundary conditions of the plate can be simplified to

$$
Z(x, \pm b, t)=0
$$

Given the assumption that the plate is infinitely long in the road direction, when $x \longrightarrow \pm \infty$,

$$
\begin{aligned}
& \lim _{x \rightarrow \pm \infty} Z_{n}(x, y, t)=0, \\
& \lim _{x \longrightarrow \pm \infty} \frac{\partial^{n} Z(x, y, t)}{\partial x^{n}}=0, \quad n=1,2,3 .
\end{aligned}
$$

Following the approach used by Zhang et al. [32], the displacement and load in equation (1) can be expanded using trigonometric series as follows:

$$
\begin{aligned}
Z(x, y, t)= & \sum_{n=1}^{\infty} Z_{n}(x, t) \sin \alpha_{n}(y+b) \\
& \approx \sum_{n=1}^{N} Z_{n}(x, t) \sin \alpha_{n}(y+b), \\
F(x, y, t)= & \sum_{n=1}^{\infty} F_{n}(x, t) \sin \alpha_{n}(y+b) \\
& \approx \sum_{n=1}^{N} F_{n}(x, t) \sin \alpha_{n}(y+b),
\end{aligned}
$$

where $\alpha_{n}=n \pi / 2 b$.

Substituting equations (4) and (5) into equation (1), we obtain the following linear differential equations:

$$
\begin{aligned}
& D\left[\frac{\partial^{2} Z_{n}(x, t)}{\partial x^{2}}-2 \alpha_{n} \frac{\partial Z_{n}(x, t)}{\partial x}+\alpha_{n}^{2} Z_{n}(x, t)\right] \\
& \quad+M \frac{\partial^{2} Z_{n}(x, t)}{\partial t^{2}}-K Z_{n}(x, t)-C Z_{n}(x, t)=F_{n}(x, t) .
\end{aligned}
$$

The solution to equation (6) is found to be

$$
Z_{n}(x, t)=e^{A_{1} x} c_{1}+e^{A_{2} x} c_{2}+\frac{-F_{n}+M a_{0.15}}{C+K-D \alpha_{n}^{2}},
$$

where $\quad A_{1}=\left(-\sqrt{D(C+K)}+D \alpha_{n}\right) / D$ and $A_{2}=$ $\left(\sqrt{D(C+K)}+D \alpha_{n}\right) / D$.

As $\lim _{x \longrightarrow \pm \infty}\left(\partial^{n} Z(x, t) / \partial x^{n}\right) \approx \lim _{x \longrightarrow \pm 0.4}\left(\partial^{n} Z(x, t) / \partial x^{n}\right)=0$, we can obtain $c_{1} \longrightarrow 0$ and $c_{2} \longrightarrow 0$.

The solution to equation (6) can be rewritten as follows:

$$
Z=\frac{-F_{n}+M a_{0.15}}{C+K-D \alpha_{n}^{2}} .
$$

For the considered load $F_{n}$ and stiffness $K$, equation (8) can be shown in the next two sections: Case A and Case B.

2.1. Case A: Single Jack. According to the established ballast vibration model [34], this paper studies a load diffusion model in the stabilised layer, as shown in Figure 2. Single jack (vibration source) is considered for the circular load with diameter $d_{1}=0.15 \mathrm{~m}$, as shown in Figure 2(a). The thickness of the asphalt layer is lower. Therefore, the load transfer largely affects the stabilised layer and the subgrade.

The load $F_{n}$ and stiffness of the asphalt layer $K_{1}$ can be expressed, respectively, as follows:

$$
\begin{aligned}
F_{n}(x, t) & =\frac{4 P\left(e^{i \omega t}-1-\ln (\omega t)\right) \zeta_{n}\left(\left(d_{1} / 2\right)+h_{2} \tan \alpha\right)^{2}}{d_{1}^{2}}, \\
K_{1} & =\frac{d_{1}}{4} E_{1},
\end{aligned}
$$

where $P$ is the excitation load, $t$ is the load time, $h_{2}$ is the thickness of the stabilised layer, $\zeta_{n}$ is a constant, $\alpha$ is the load distribution angle [34], and $E_{1}$ is the elastic modulus of the 


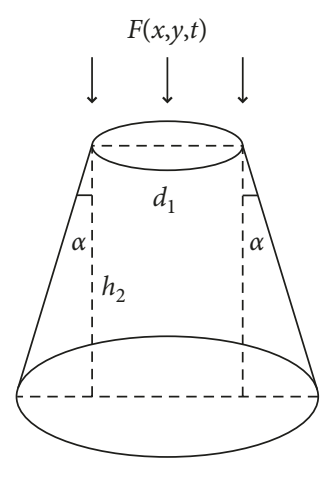

(a)

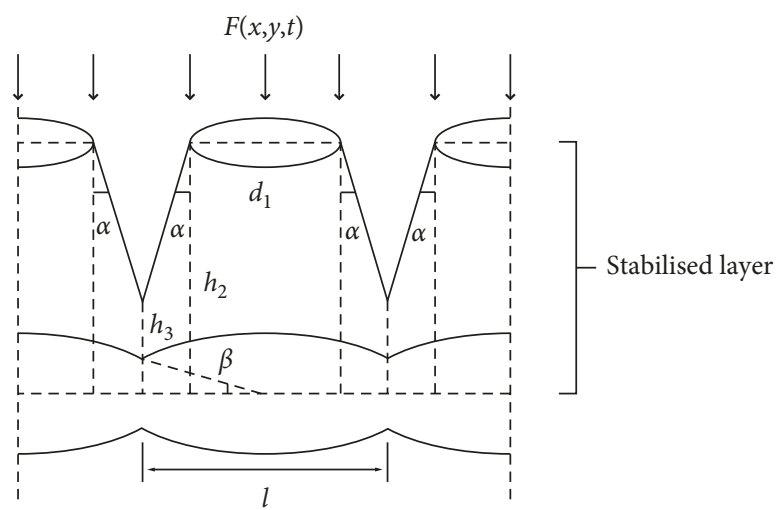

(b)

Figure 2: Load diffusion model: (a) single jack and (b) three jacks.

asphalt layer. In addition, $i=-1, \omega=2 \pi f$, and $f$ is the excitation frequency.

For the load transmission of single jack, as shown in Figure 2(a), the stiffness of the stabilised layer $K_{2}$ can be expressed as follows:

$$
K_{2}=\frac{\pi d_{1}^{3} \tan \alpha}{4\left(\left(d_{1} / 2\right)+h_{2} \tan \alpha\right)^{2}} E_{2},
$$

where $E_{2}$ is the elastic modulus of the stabilised layer.

Furthermore, the stiffness of the subgrade $K_{3}$ under single vibration source can be defined as follows:

$$
K_{3}=\frac{d_{1}+2 h_{2} \tan \alpha}{4} E_{3},
$$

where $E_{3}$ is the elastic modulus of the filling medium in the subgrade.

2.2. Case B: Three Jacks. As shown in Figure 2(b), the load diffusion model of the three jacks (vibration sources) is based on the assumption of single jack. In the case of the thickness of the stabilised layer, if the spacing between the adjacent vibration sources is small enough, an overlapping of the adjacent load distribution may occur. The height of the overlapping regions is defined as $h_{3}$.

The stiffness of the stabilised layer $K_{2}$ consists of two parts in series:

$$
K_{2}=\frac{K_{21} K_{22}}{K_{21}+K_{22}},
$$

where

$$
\begin{aligned}
& K_{21}=\frac{\pi d_{1}^{3} \tan \alpha}{l^{2}} E_{2}, \\
& K_{22}=\frac{l^{3} \pi^{2} \tan \alpha}{2 l^{2} \tan \beta+8\left(d_{1}+2 h_{2} \tan \alpha\right)^{2} \pi\left(180^{\circ}-2 \beta / 180^{\circ}\right)} E_{2},
\end{aligned}
$$

where $l$ is the vibration source spacing and $\beta=$ $\arccos \left(l / d_{1}+2 h_{2} \tan \alpha\right), \in\left(0^{\circ}, 90^{\circ}\right)$.

The stiffness of the subgrade $K_{3}$ and load $F_{n}$ under three vibration sources can be rewritten as follows:

$$
\begin{aligned}
K_{3} & =\frac{l^{2} \tan \beta+\pi\left(d_{1}+2 h_{2} \tan \alpha\right)^{2}\left(180^{\circ}-2 \beta / 180^{\circ}\right)}{4\left(d_{1}+2 h_{2} \tan \alpha\right)\left(\left(180^{\circ}-2 \beta / 180^{\circ}\right) \pi+\sin \beta\right)} E_{3}, \\
F_{n}(x, t) & =\frac{6 P\left(e^{i \omega t}-1-\ln (\omega t)\right) \zeta_{n}\left(l^{2} \tan \beta+\pi\left(d_{1}+2 h_{2} \tan \alpha\right)^{2}\left(180^{\circ}-2 \beta / 180^{\circ}\right)\right)}{\pi d_{1}^{2}} .
\end{aligned}
$$

\section{Test Devices and Materials}

Figure 3 shows the model structures and layout of the scaled test, including an asphalt layer, a stabilised layer, four displacement meters, five three-way capacitive accelerometers, and ten soil pressure cells. The displacement meters are arranged at the centre of the vibration source and at the boundary of the plate. The five accelerometers and the five central soil pressure cells are set in the vertical direction of the vibration source with a vertical distance of $0.15 \mathrm{~m}$. The adjacent vertical spacing between the slope soil pressure cells is $0.15 \mathrm{~m}$, and their horizontal distances to the load centre are $0.3,0.4,0.5,0.6$, and $0.7 \mathrm{~m}$. In Figure 3 , the dynamic load is simulated by varying the number of hydraulic jacks, and the adjacent spacing is $0.175 \mathrm{~m}$. The dynamic behavior of the subgrade is studied by measuring the acceleration and effective soil pressure. The displacement of the elastic doublelayer plate on the viscoelastic subgrade is analysed using the 


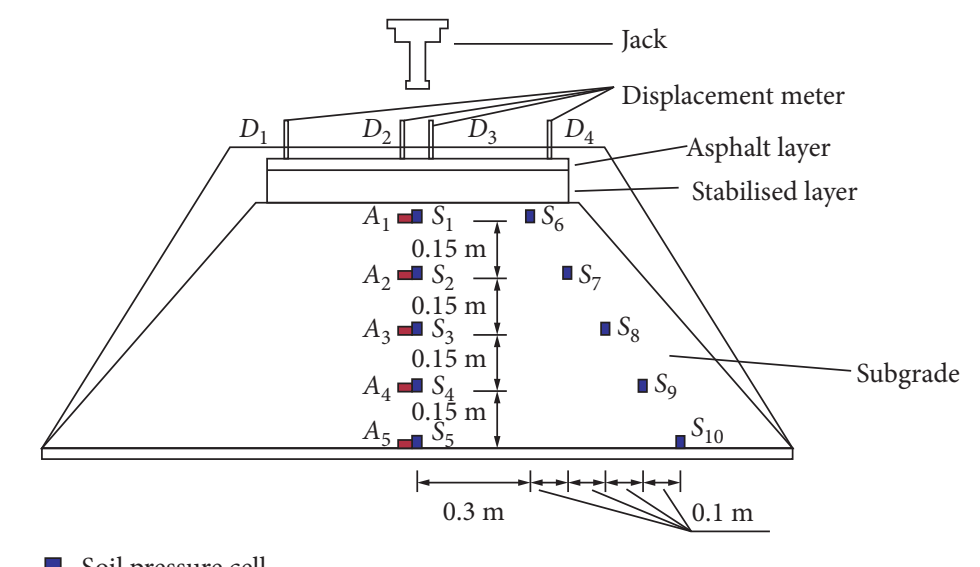

Soil pressure cell

Accelerometer

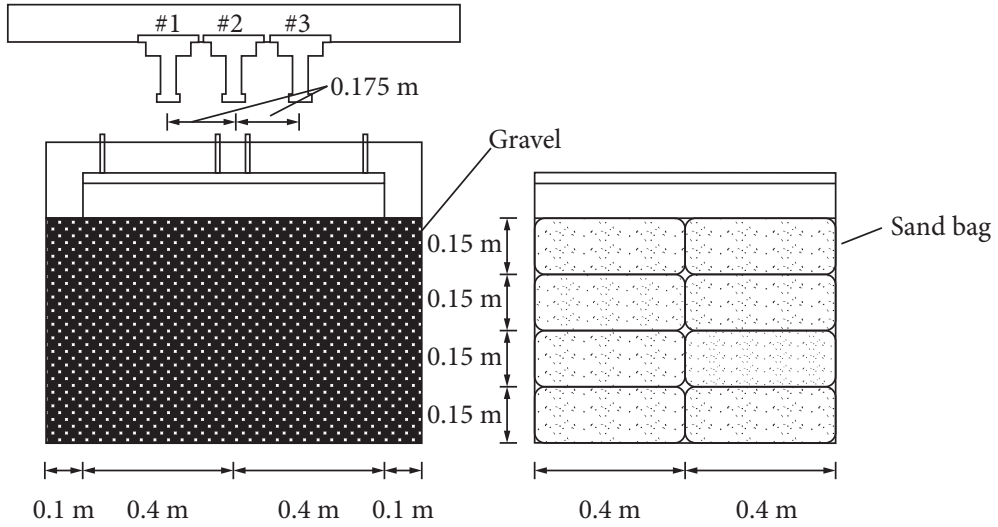

FIgUre 3: Model structures and layout of scaled test.

displacement meter. The subgrade filling medium is divided into sand bag and gravel. The typical size of each sand bag (river sand) is $40 \mathrm{~cm} \times 40 \mathrm{~cm} \times 12 \mathrm{~cm}$. The weight of each sand bag is $20.0 \mathrm{~kg}$, which are sealed with portable sewing machine. The sand bags are stacked in four layers and each with four. The gaps between the sand bags are filled with the same material as that in the bags; this filler material is used to stabilise the test components, as shown in Figure 3. The main factors that affect the dynamic response include the subgrade filling material, vibration load, vibration frequency, and number of jacks. In this experiment, the sand bags and gravel are selected as the subgrade filling medium. The excitation load and excitation frequency are, respectively, set to 2000, 3500 , and $5000 \mathrm{~N}$ and $1,5,10$, and $15 \mathrm{~Hz}$. The conditions of single ack and three jacks are considered separately in this work. Table 1 lists the relevant parameters of the filling medium in the subgrade, mainly including the resilient modulus, Poisson's ratio, damping constant, internal friction angle, height, and particle size. Table 2 lists some parameters of the asphalt and stabilised layers. Tables 3-5 list some parameters of the displacement meter, the three-way capacitive accelerometer, and the soil pressure cell, respectively.

\section{Validation and Comparison}

To study the dynamic response of the road, the subgrade filled with sand bag and gravel is used for testing in the experiment. The purpose of changing the number of jacks is to study the superposition effect of regions under multiple vibration sources. By adjusting the excitation load and frequency through the control system, the influence of different loads on the dynamic response of the road can be obtained.

4.1. Displacement. Figure 4 shows the variation in the displacement with respect to time for excitation frequencies $(f)$ of $1,5,10$, and $15 \mathrm{~Hz}(P=5000 \mathrm{~N})$. Figures $4(\mathrm{a})$ and 4 (b) show the displacements of the elastic double-layer plate under single jack and three jacks conditions, respectively. Figure 4 shows that there is a relatively good agreement between the theoretical calculation results and the test data. The theoretical calculation curve reflects the correspondence between the frequency and the displacement, and the theoretical formulae under the single and three jacks conditions are respectively expressed as follows:

$$
\begin{aligned}
& Z=5.7 \times 10^{-6}\left[181.44 a_{0.15}+5012\left(1-e^{2 \pi f t}+\ln (2 \pi f t)\right)\right] \\
& Z=6.7 \times 10^{-6}\left[181.44 a_{0.15}+6211\left(1-e^{2 \pi f t}+\ln (2 \pi f t)\right)\right]
\end{aligned}
$$

where $a_{0.15}$ denotes the peak acceleration under different excitation frequencies, which are listed in Table 6. 
TABle 1: Parameters of the subgrade.

\begin{tabular}{lcccccccc}
\hline $\begin{array}{l}\text { Filling } \\
\text { medium in } \\
\text { subgrade }\end{array}$ & $\begin{array}{c}\text { Resilient } \\
\text { modulus, } E_{3} \\
(\mathrm{MPa})\end{array}$ & $\begin{array}{c}\text { Poisson's } \\
\text { ratio, } \mu_{3}\end{array}$ & $\begin{array}{c}\text { Damping } \\
\text { constant, } C_{3} \\
(\mathrm{Ns} / \mathrm{m})\end{array}$ & $\begin{array}{c}\text { Internal } \\
\text { friction } \\
\text { angle, } \theta\left(^{\circ}\right)\end{array}$ & $\begin{array}{c}\text { Height of } \\
\text { subgrade, } H_{0} \\
(\mathrm{~m})\end{array}$ & $>1 \mathrm{~mm}$ & $\begin{array}{c}\text { Particle size }(\%) \\
1-0.25 \mathrm{~mm}\end{array}$ & $\begin{array}{c}0.25-0.075 \mathrm{~mm} \\
<0.075 \mathrm{~mm}\end{array}$ \\
\hline Sand bag & 80 & 0.35 & $3.5 \times 10^{4}$ & 30 & 0.6 & 6.25 & 93.35 & 0.3 \\
Gravel & 180 & 0.35 & $4.8 \times 10^{4}$ & 30 & 0.6 & 95.3 & 2.85 & 1.5 \\
\hline
\end{tabular}

TABLE 2: Parameters of the elastic double-layer plate.

\begin{tabular}{lc}
\hline Thickness of the asphalt layer $h_{1}(\mathrm{~m})$ & 0.03 \\
Thickness of the stabilised layer $h_{2}(\mathrm{~m})$ & 0.09 \\
Resilient modulus of the asphalt layer, $E_{1}(\mathrm{MPa})$ & 1500 \\
Resilient modulus of the stabilised layer, $E_{2}(\mathrm{MPa})$ & 1200 \\
Poisson's ratio of the asphalt layer, $\mu_{1}$ & 0.35 \\
Poisson's ratio of the stabilised layer, $\mu_{2}$ & 0.35 \\
Damping constant of the asphalt layer, $C_{1}(\mathrm{Ns} / \mathrm{m})$ & $3.7 \times 10^{4}$ \\
Damping constant of the stabilised layer, $C_{2}(\mathrm{Ns} / \mathrm{m})$ & $5 \times 10^{4}$ \\
Density of the asphalt layer, $\rho_{1}\left(\mathrm{~kg} / \mathrm{m}^{3}\right)$ & 2400 \\
Density of the stabilised layer, $\rho_{2}\left(\mathrm{~kg} / \mathrm{m}^{3}\right)$ & 2350 \\
Length of the asphalt layer, $2 b(\mathrm{~m})$ & 0.8 \\
Length of the stabilised layer, $2 b(\mathrm{~m})$ & 0.8 \\
Diameter of the load contact surface, $d_{1}(\mathrm{~m})$ & 0.15 \\
Load distribution angle, $\alpha\left({ }^{\circ}\right)$ & 30 \\
Vibration source spacing, $l(\mathrm{~m})$ & 0.175 \\
Constant, $\zeta_{1}$ & 0.35 \\
Constant, $\zeta_{3}$ & 0.113 \\
\hline
\end{tabular}

TABle 3: Parameters of the displacement meter.

\begin{tabular}{lcccc}
\hline Test point & Sensitivity $(\mathrm{mm})$ & Range $(\mathrm{mm})$ & Accuracy $(\mathrm{mm})$ & \\
\hline$D_{1}$ & 0.0762 & & & Resolution $(\mathrm{mm})$ \\
$D_{2}$ & 0.0751 & 100 & $\geq 0.3 \%$ & 0.0125 \\
$D_{3}$ & 0.0756 & & & \\
$D_{4}$ & 0.0737 & & & \\
\hline
\end{tabular}

TABle 4: Parameters of the three-way capacitive accelerometer.

\begin{tabular}{lcccc}
\hline Test point & $Z$-axis sensitivity $\left(\mathrm{m} / \mathrm{s}^{2}\right)$ & Range $(\mathrm{g})$ & Transverse sensitivity ratio $(\%)$ & Resonant frequency $(\mathrm{kHz})$ \\
\hline$A_{1}$ & 66.9 & & & \\
$A_{2}$ & 67.2 & & $<5$ & 12 \\
$A_{3}$ & 67.3 & \pm 2 & & \\
$A_{4}$ & 66.1 & & \\
$A_{5}$ & 67.9 & & \\
\hline
\end{tabular}

TABLe 5: Parameters of the soil pressure cell.

\begin{tabular}{lcccccc}
\hline $\begin{array}{l}\text { Test } \\
\text { point }\end{array}$ & $\begin{array}{c}\text { Calibration } \\
\text { coefficient }(\mathrm{KPa})\end{array}$ & $\begin{array}{c}\text { Range } \\
(\mathrm{KPa})\end{array}$ & Sensitivity coefficient & Test point & Calibration coefficient (KPa) Range (KPa) Sensitivity coefficient \\
\hline$S_{1}$ & 0.2273 & & & $\mathrm{~S}_{6}$ & 0.2083 & 0.25 \\
$S_{2}$ & 0.2174 & & & $\mathrm{~S}_{7}$ & 0.2717 & $0-100$ \\
$S_{3}$ & 0.2632 & $0-100$ & 2.0 & $\mathrm{~S}_{8}$ & 0.2778 & 2.0 \\
$S_{4}$ & 0.25 & & & $\mathrm{~S}_{9}$ & 0.2632 & \\
$S_{5}$ & 0.2273 & & & $\mathrm{~S}_{10}$ & & \\
\hline
\end{tabular}

Figure 5 shows the variation in the displacement with respect to time under different excitation loads $(2000 \mathrm{~N}$, $3500 \mathrm{~N}$, and $5000 \mathrm{~N}$ ) for an excitation frequency of $10 \mathrm{~Hz}$.
For comparison, the theoretical results are also plotted in the figures, and the theoretical formulae for the two cases can be respectively written as follows: 


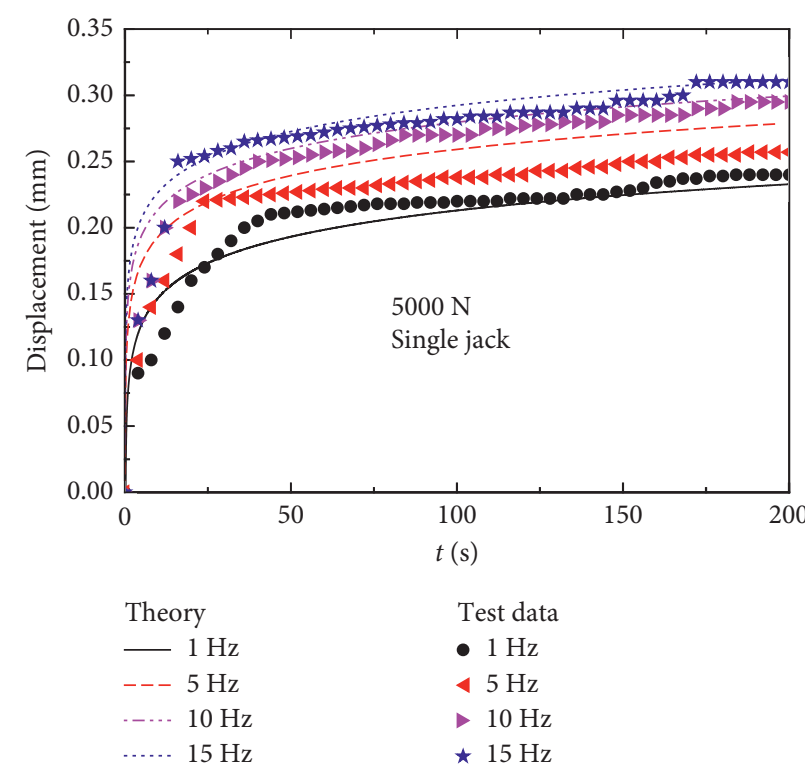

(a)
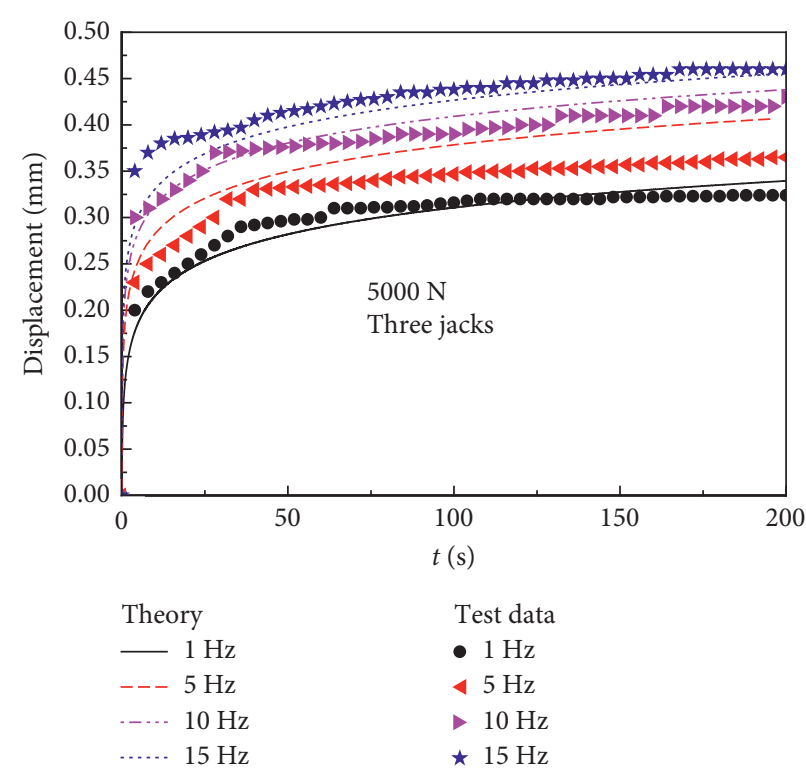

Test data

- $1 \mathrm{~Hz}$

$45 \mathrm{~Hz}$

- $10 \mathrm{~Hz}$

$\star 15 \mathrm{~Hz}$

(b)

Figure 4: Displacement versus time curves under different excitation frequencies (sand bag): (a) single jack and (b) three jacks.

TABLE 6: Acceleration $a_{0.15}\left(\mathrm{~m} / \mathrm{s}^{2}\right)$.

\begin{tabular}{lccccccc}
\hline Filling medium in subgrade & $\begin{array}{c}\text { Number of } \\
\text { jacks, } n\end{array}$ & $5000 \mathrm{~N}-1 \mathrm{~Hz}$ & $5000 \mathrm{~N}-5 \mathrm{~Hz}$ & $5000 \mathrm{~N}-10 \mathrm{~Hz}$ & $5000 \mathrm{~N}-15 \mathrm{~Hz}$ & $\begin{array}{c}2000 \\
N-10 \mathrm{~Hz}\end{array}$ & $\begin{array}{c}3500 \\
N-10 \mathrm{~Hz}\end{array}$ \\
\hline \multirow{2}{*}{ Sand bag } & 1 & 0.39 & 0.57 & 1.23 & 2.31 & 0.39 \\
& 3 & 0.8 & 1.49 & 3 & 0.65 \\
Gravel & 1 & - & - & 1.16 & - & 0.97 & 2.17 \\
\hline
\end{tabular}

$$
\begin{aligned}
& Z=5.7 \times 10^{-6}\left[181.44 a_{0.15}+1.0025 P\left(1-e^{20 \pi t}+\ln (20 \pi t)\right)\right] \\
& Z=6.7 \times 10^{-6}\left[181.44 a_{0.15}+1.2422 P\left(1-e^{20 \pi t}+\ln (20 \pi t)\right)\right]
\end{aligned}
$$

As shown in Figure 5, it is worth mentioning that the results are largely in good agreement. For a given number of jacks, the displacement of the elastic double-layer plate increases with the increase in the excitation load. Furthermore, the displacement under three jacks is higher than that under single jack. To further verify the practicability of the theoretical derivation, another filling medium in the subgrade (gravel) is selected, as shown in Figure 6. Tables 2 and 3 list the related parameters. Overall, the elastic double-layer plate model has a relatively good agreement with the experiments. However, because of the limited variables selected for the experiments, the numerical results cannot be concretely verified. In the following experiments, we discuss the theory of elastic double-layer plate on a viscoelastic subgrade in a more comprehensive manner.

Here, we now compare the test data under three jacks with three times that subjected to single jack $(P=5000 \mathrm{~N}$, $f=10 \mathrm{~Hz}$ ). As shown in Figure $7(\mathrm{a})$, the maximum displacements in the case of the sand bag are $0.43 \mathrm{~mm}$ and
$0.89 \mathrm{~mm}$ for the former and latter, respectively. In addition, it is found that the maximum displacement in the case of gravel is, respectively, equal to $0.42 \mathrm{~mm}$ and $0.83 \mathrm{~mm}$, as shown in Figure 7(b). It is noted that the displacement of the elastic double-layer plate under the three jacks condition cannot be estimated simply by multiplying the parameters associated with the single jack by three times.

An empirical formula for calculating the cumulative deformation $Z$ of the elastic double-layer plate can be expressed as follows [35]:

$$
Z=Z_{0}\left[1+c \ln (2 \pi f t)+0.5 d \ln (2 \pi f t)^{2}\right],
$$

where $Z_{0}$ is defined as the rebound displacement when the deformation gradually becomes stable $(P=5000 \mathrm{~N}, f=10 \mathrm{~Hz})$. Figure 8 shows the variation in the rebound displacement in the time interval $80-110 \mathrm{~s}$. It is found that the rebound displacement $Z_{0}$ under the single jack and three jacks conditions are 0.2 and $0.31 \mathrm{~m}$ and 0.17 and $0.28 \mathrm{~m}$ when the sand bag and gravel are used as the filling medium in the subgrade, respectively. In addition, $c$ and $d$ are two parameters.

The following equation is an alternative empirical approach to calculate $Z$ [29]:

$$
Z=Z_{0}\left(1-e^{-2 a \pi f t}\right)+b \ln (2 \pi f t)
$$

where $a$ and $b$ are two parameters. 

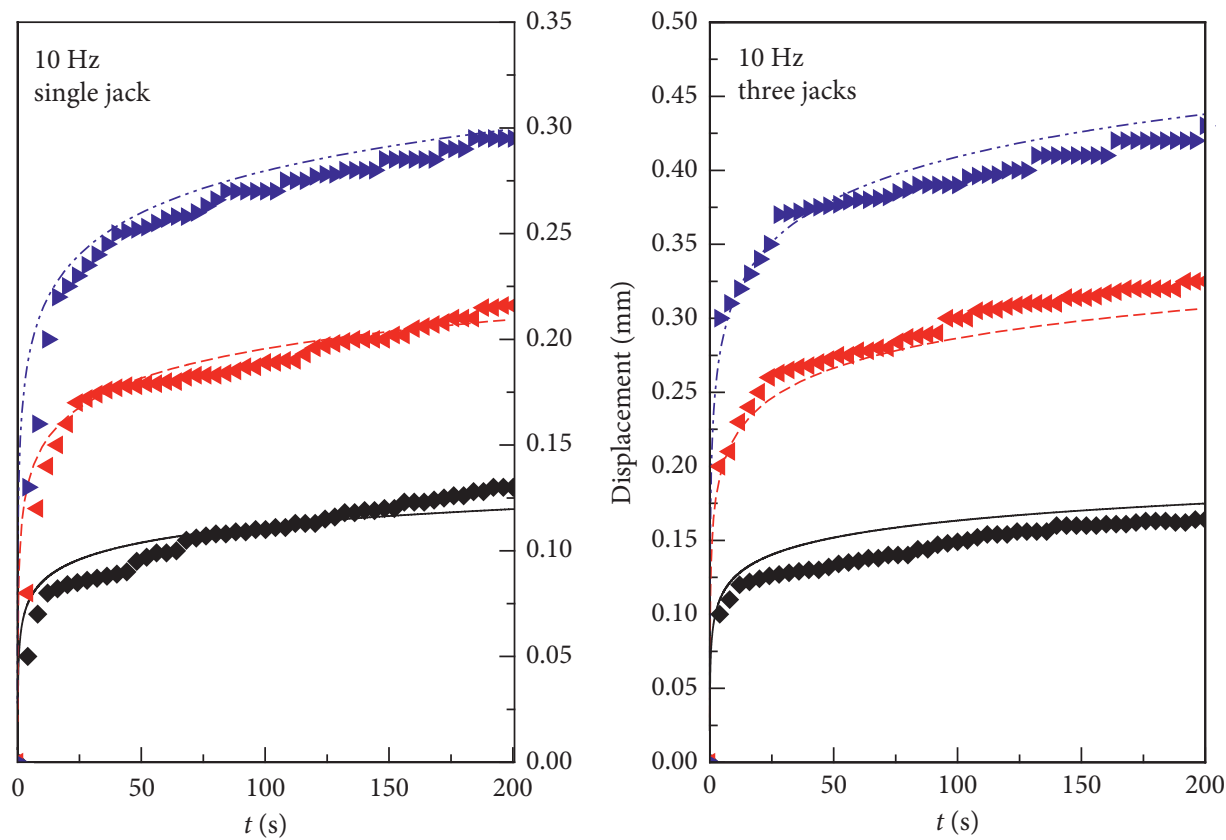

$\begin{array}{ll}\text { Test data } & \text { Theory } \\ -2000 \mathrm{~N} & -2000 \mathrm{~N} \\ <3500 \mathrm{~N} & --3500 \mathrm{~N} \\ -5000 \mathrm{~N} & \text {-. } 5000 \mathrm{~N}\end{array}$

(a)

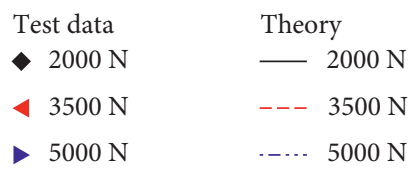

(b)

FIgURE 5: Displacement versus time curves under different excitation loads (sand bag): (a) single jack and (b) three jacks.
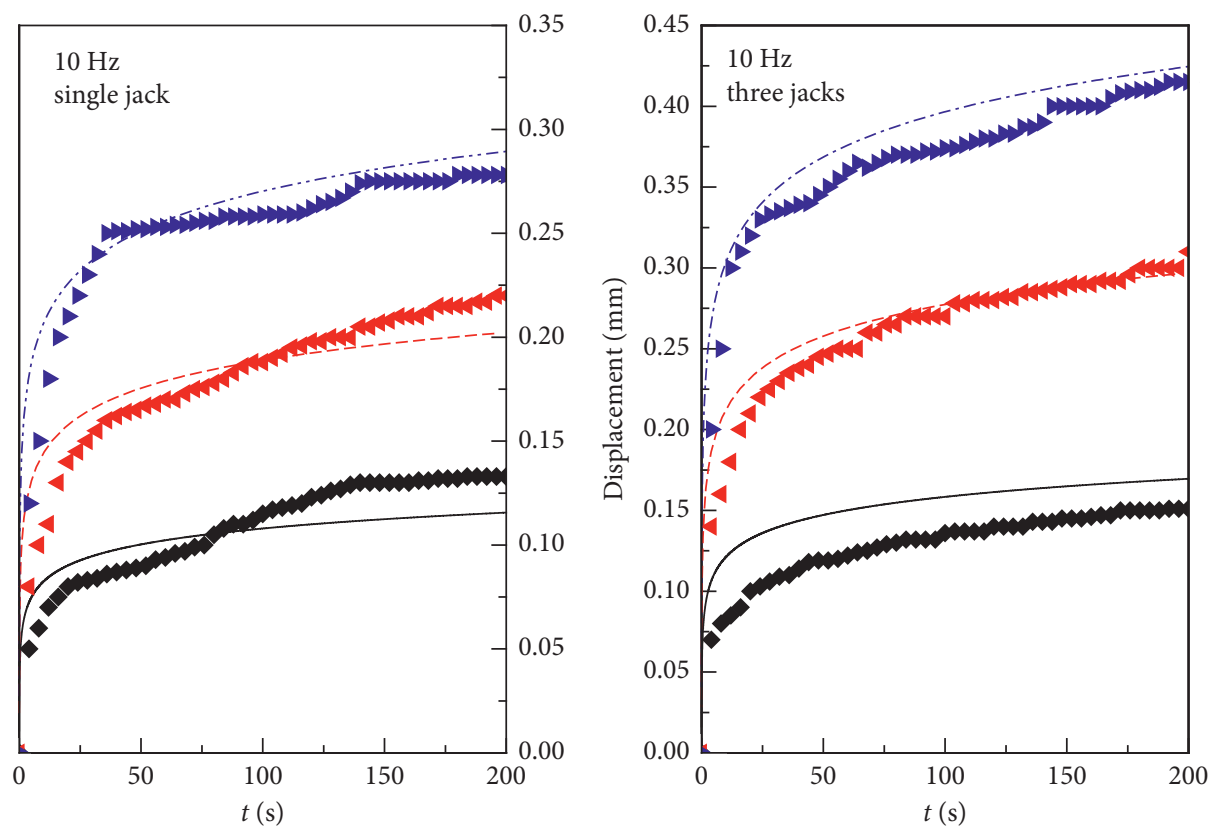

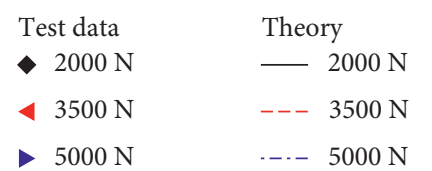

(a)

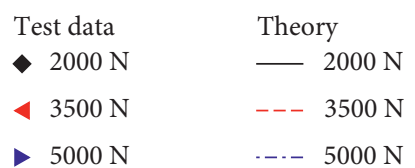

(b)

FiguRe 6: Displacement versus time curves under different excitation loads (gravel): (a) single jack and (b) three jacks. 


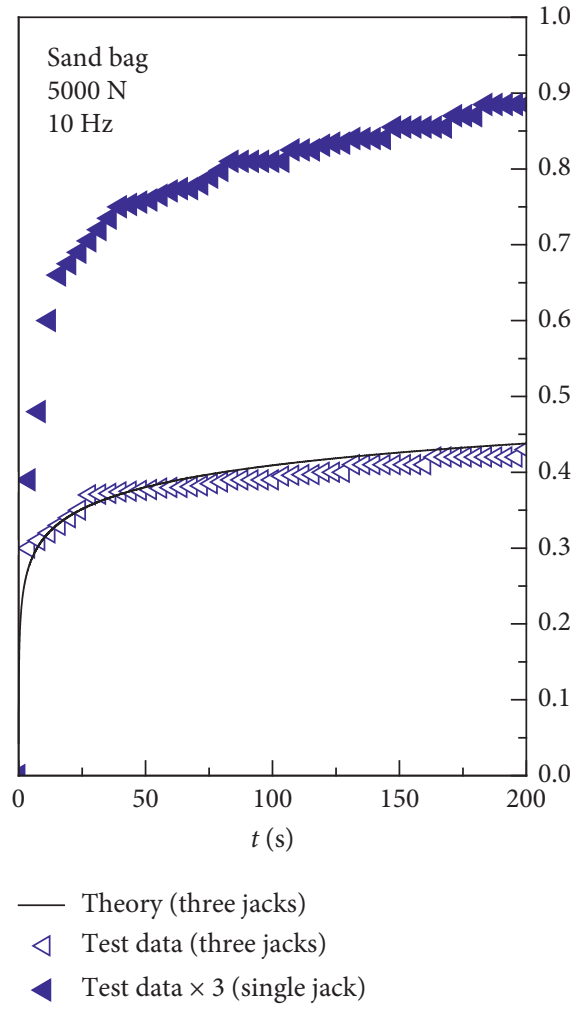

(a)

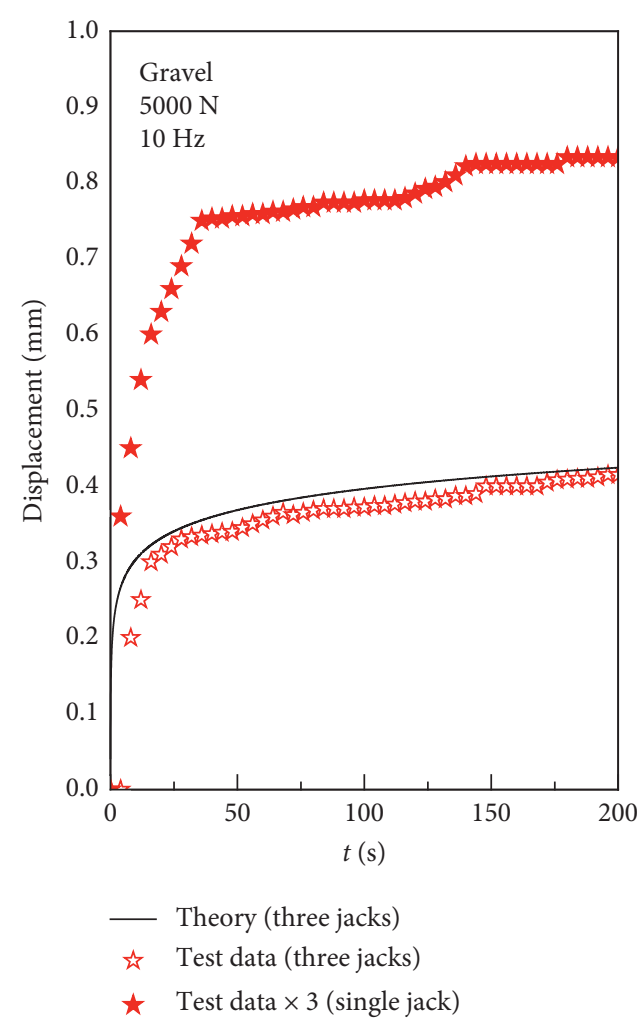

(b)

FIgURE 7: Variation in the displacement versus time curves: (a) sand bag and (b) gravel.

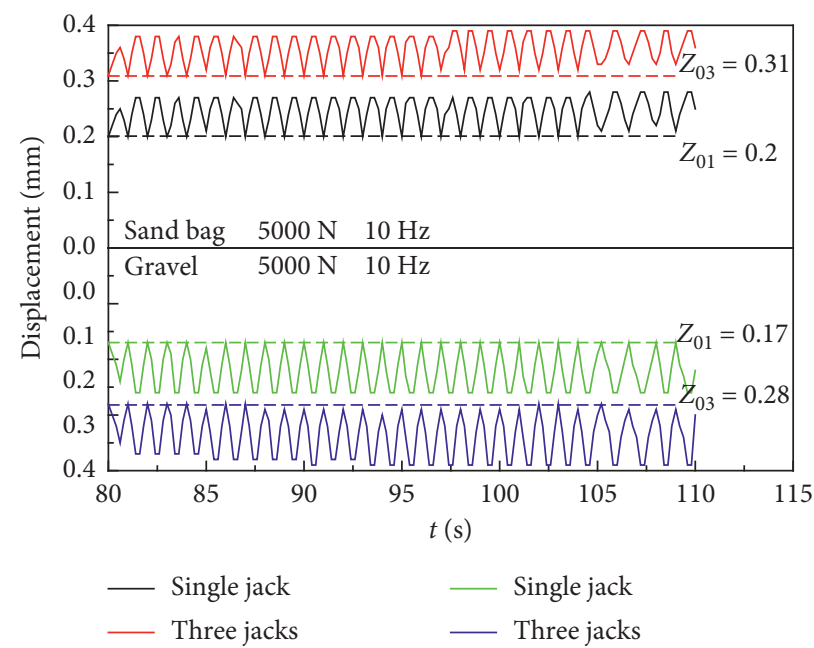

Figure 8: Rebound displacement $Z_{0}$.

Figure 9 presents the comparisons of the displacements obtained from the empirical formulae (17) and (18), equation (8), and test data (sand bag). The test data have a certain nonlinear relationship with the theoretical formula. Moreover, there is a strong consistency between the empirical formulae and the test data under both single jack and three jacks conditions. To further verify the relationship between the theoretical formula, empirical formulae, and test data, an alternative filling medium in the subgrade (gravel) is selected, as shown in Figure 10. The results have a strong consistency. In other words, the theoretical formula for the elastic doublelayer plate is thoroughly verified via this experiment. Moreover, empirical formulae (17) and (18) were effectively applied.

4.2. Effective Soil Pressure. Under the above loading conditions, the effective soil pressure in the subgrade medium $\delta_{\mathrm{C}}$ can be expressed as follows: 

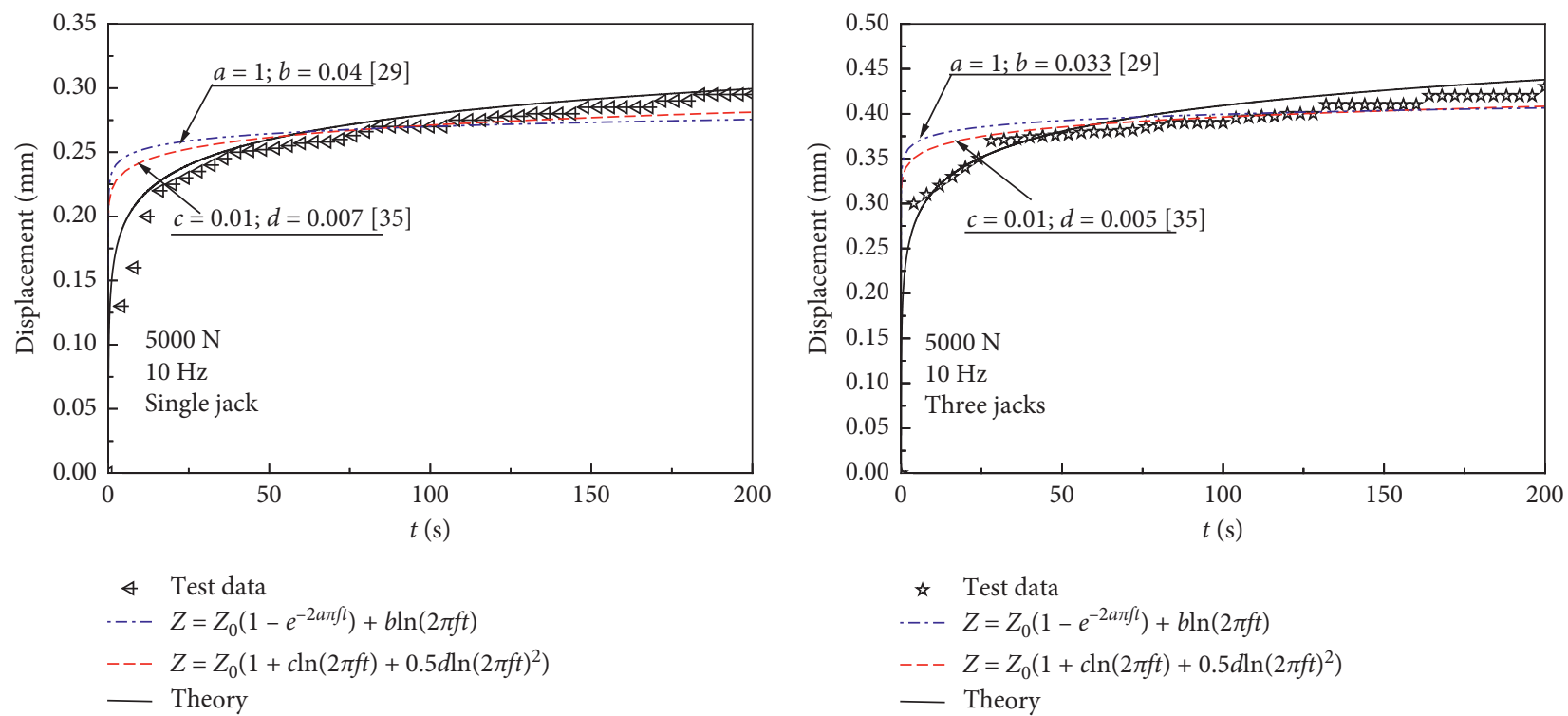

(a)

(b)

FIgURE 9: Variation in the displacement versus time curves (sand bag): (a) single jack and (b) three jacks.

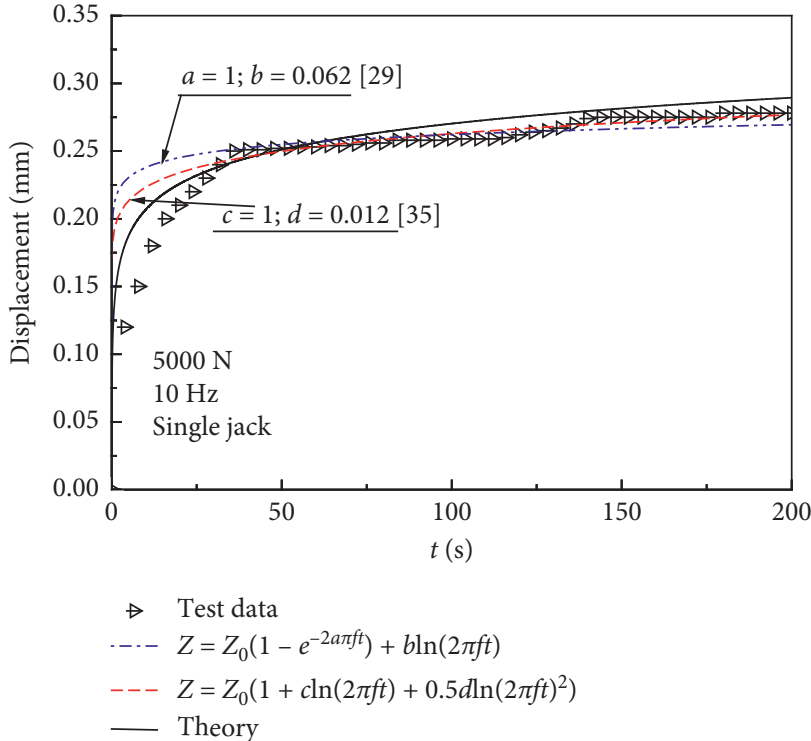

(a)

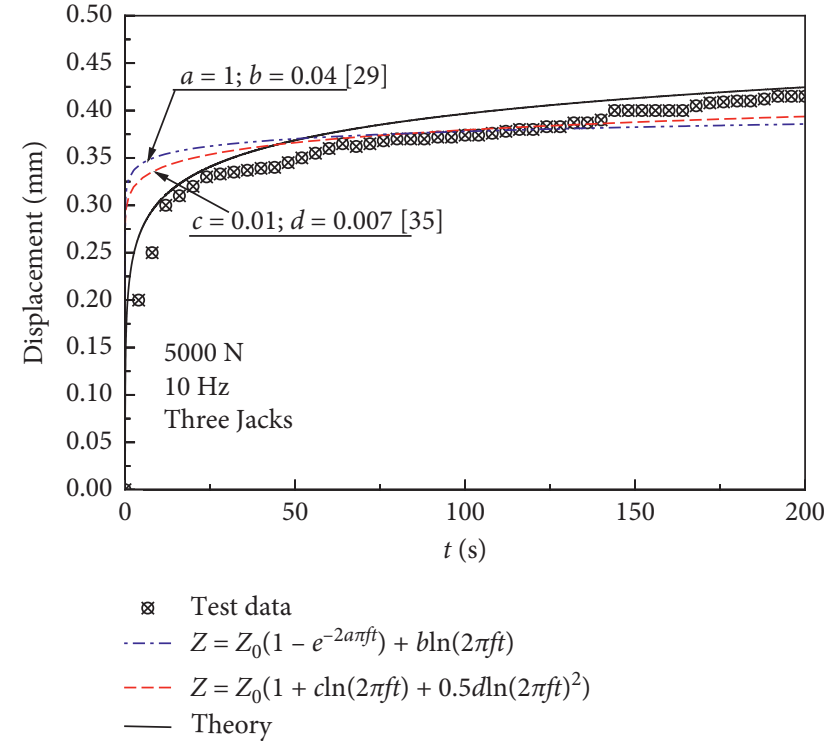

(b)

Figure 10: Variation in the displacement versus time curve (gravel): (a) single jack and (b) three jacks.

$$
\delta_{\mathrm{C}}=e^{(H-h / H)}\left(p \delta_{0}+q \frac{F_{n}(x, t)}{S}\right) n,
$$

where $H$ is the height of the vibration source, $h$ is the embedded depth of the sensor, $S$ is the effective loading area on the top of the subgrade, $n$ is the number of jacks, and $p$ and $q$ are two parameters. It is also assumed that the initial effective soil pressure $\delta_{0}=0$.

The embedded depth of the soil pressure cells, $h$, is a parameter found to be important enough to affect the dynamic response of the subgrade. Therefore, the depth $h$ with values of $0.15,0.3,0.45,0.6$, and $0.75 \mathrm{~m}$ is set during the test process. The simulations are conducted in load cycles of 200 s. Figures 11(a) and 11(b) show the comparisons of the effective soil pressure with respect to different depths under the single jack and three jacks conditions, respectively. As expected, the effective soil pressure decreases with the increase in the depth $h$. It is found that the theoretical formula most closely matches the test data when $h=0.45 \mathrm{~m}$. The theoretical formulae, shown in Figure 11, for the single jack and three jacks conditions are expressed as follows, respectively: 


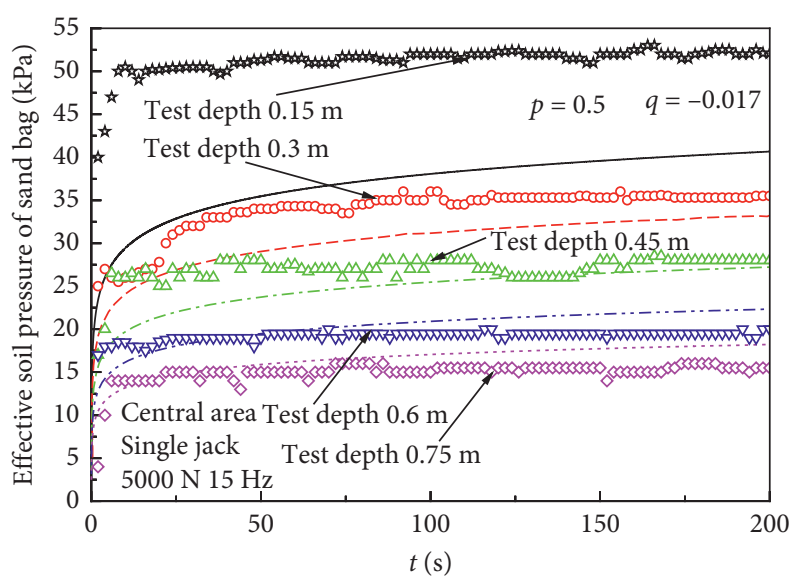

Theory

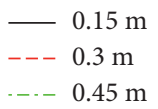

$-\cdots 0.6 \mathrm{~m}$

$0.75 \mathrm{~m}$

(a)

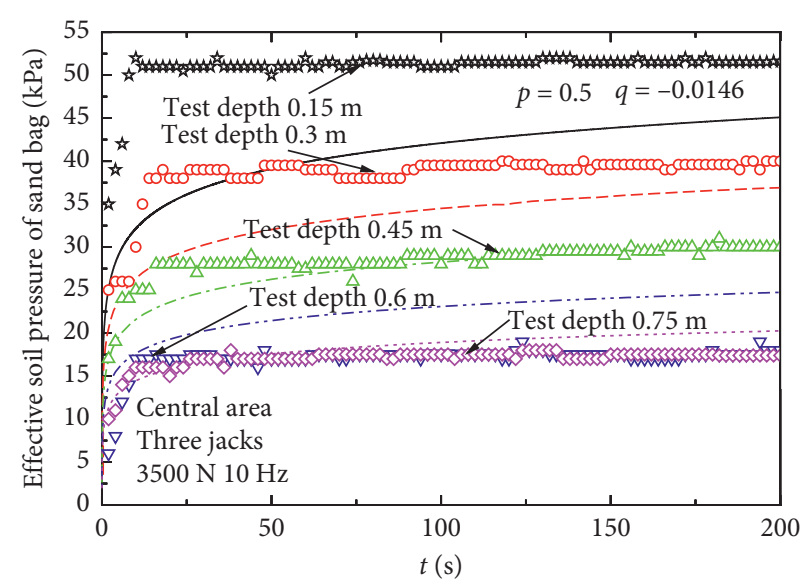

Theory

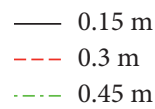

$0.75 \mathrm{~m}$

(b)

FiguRE 11: Variation in the effective soil pressure versus time curve at different measurement points (sand bag): (a) single jack and (b) three jacks.

$$
\begin{aligned}
& \delta_{\mathrm{C}}=1.7 e^{(0.75-h / 0.75)}\left[1-e^{-30 \pi t}+\ln (30 \pi t)\right] \quad(\text { a single jack }) \\
& \delta_{\mathrm{C}}=1.94 e^{(0.75-h / 0.75)}\left[1-e^{-20 \pi t}+\ln (20 \pi t)\right](\text { three jacks })
\end{aligned}
$$

Figure 12 shows the effective soil pressure under different excitation loads obtained from the theoretical analysis compared to the test data for $h=0.45 \mathrm{~m}$ and $f=15 \mathrm{~Hz}$. The results obtained from the theoretical formula are in good agreement with the test data under different excitation loads. In addition, the results show that the effective soil pressure increases with an increase in the excitation load under both single jack and three jacks conditions.

Generally, the effective soil pressure under single jack is lower than that under three jacks. Undoubtedly, this is a result of "effective superposition effect" induced by the joint action of multiple loads, thereby increasing the dynamic response of the subgrade. However, the effective soil pressure under the three jacks condition cannot be estimated simply by multiplying the parameters associated with the single jack by three times.

Figure 13(a) shows the effective soil pressure under different excitation frequencies obtained from the theoretical analysis compared with the test data. It is found that the effective soil pressure increases with an increase in the excitation frequency in the case of the single jack. However, the results obtained from the theoretical formula are different from the test data. The relative errors between the theoretical maximum effective soil pressure and the test data are $7.44 \%$, $14.1 \%, 3 \%$, and $6.7 \%$ for $f=1,5,10$, and $15 \mathrm{~Hz}$, respectively. The theoretical formula is written as follows:

$$
\delta_{\mathrm{C}}=103467 q\left[-1+e^{-2 \pi f t}-\ln (2 \pi f t)\right] .
$$

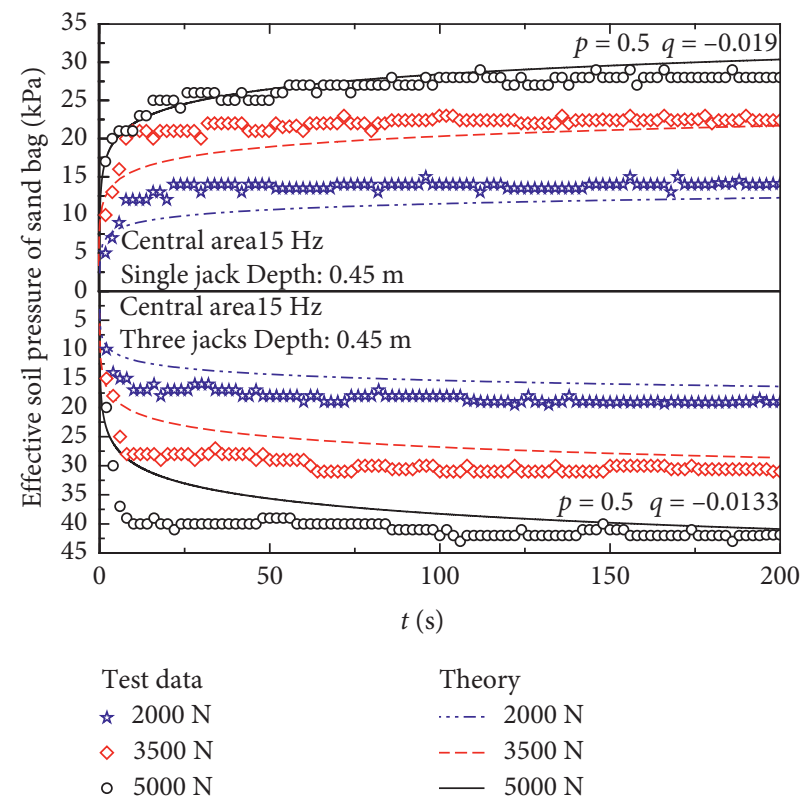

FIGURE 12: Variation in the effective soil pressure versus time curve under different excitation loads (sand bag).

The parameter $q$ is very important for determining the effective soil pressure. As shown in Figure 13(b), the variations in the effective soil pressure with respect to time under $f=1,5,10$, and $15 \mathrm{~Hz}$ are, respectively, plotted when $q$ is equal to $-0.017,-0.017,-0.019$, and -0.02 . The test data are found to closely match the theoretical curves.

Figures 14(a) and 14(b) compare the measured effective soil pressures under different excitation loads under the single jack and three jacks conditions for subgrades filled 

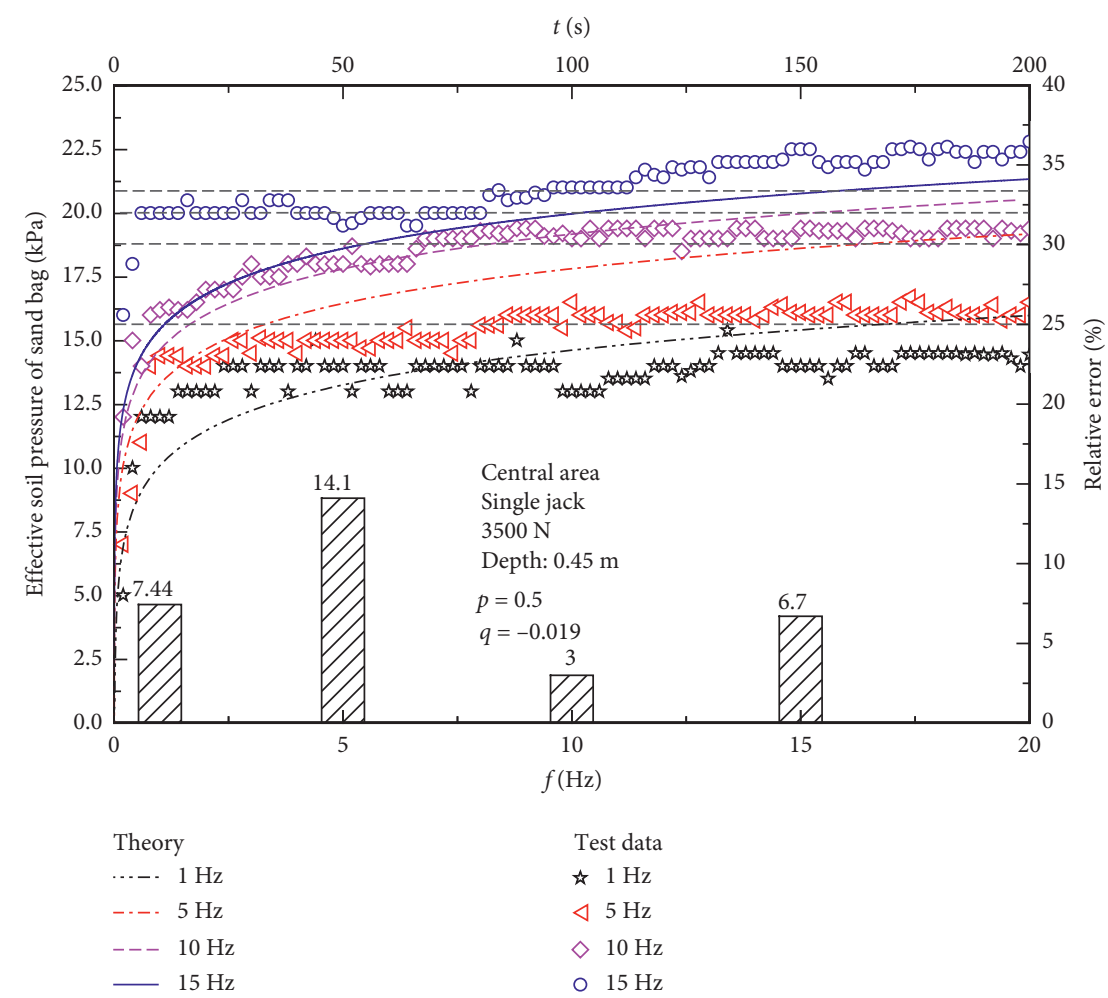

(a)
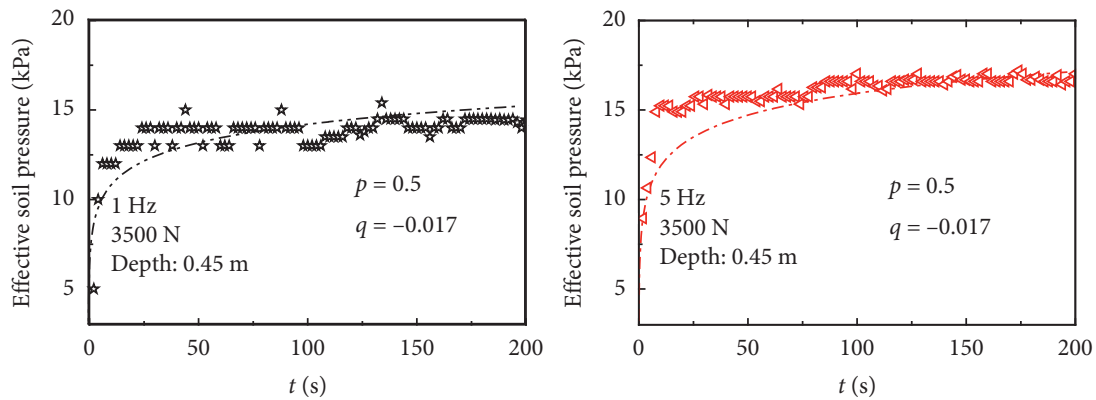

* Test data

\ Test data

.... Theory

-.-. Theory
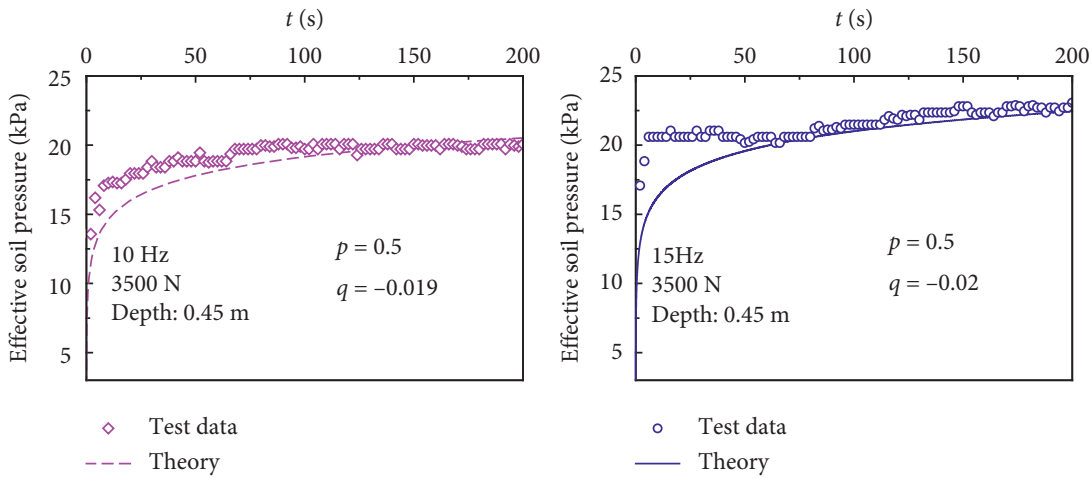

(b)

FIGURE 13: Variation in the effective soil pressure versus time curve under different excitation frequencies (sand bag).

with sand bag and gravel, respectively. The gaps between the sand bags are filled with the soil. The figures show that the effective soil pressure increases significantly with the increase in the excitation load, particularly when three jacks are used. In addition, the effective soil pressure increases with the increase in the excitation frequency when the 

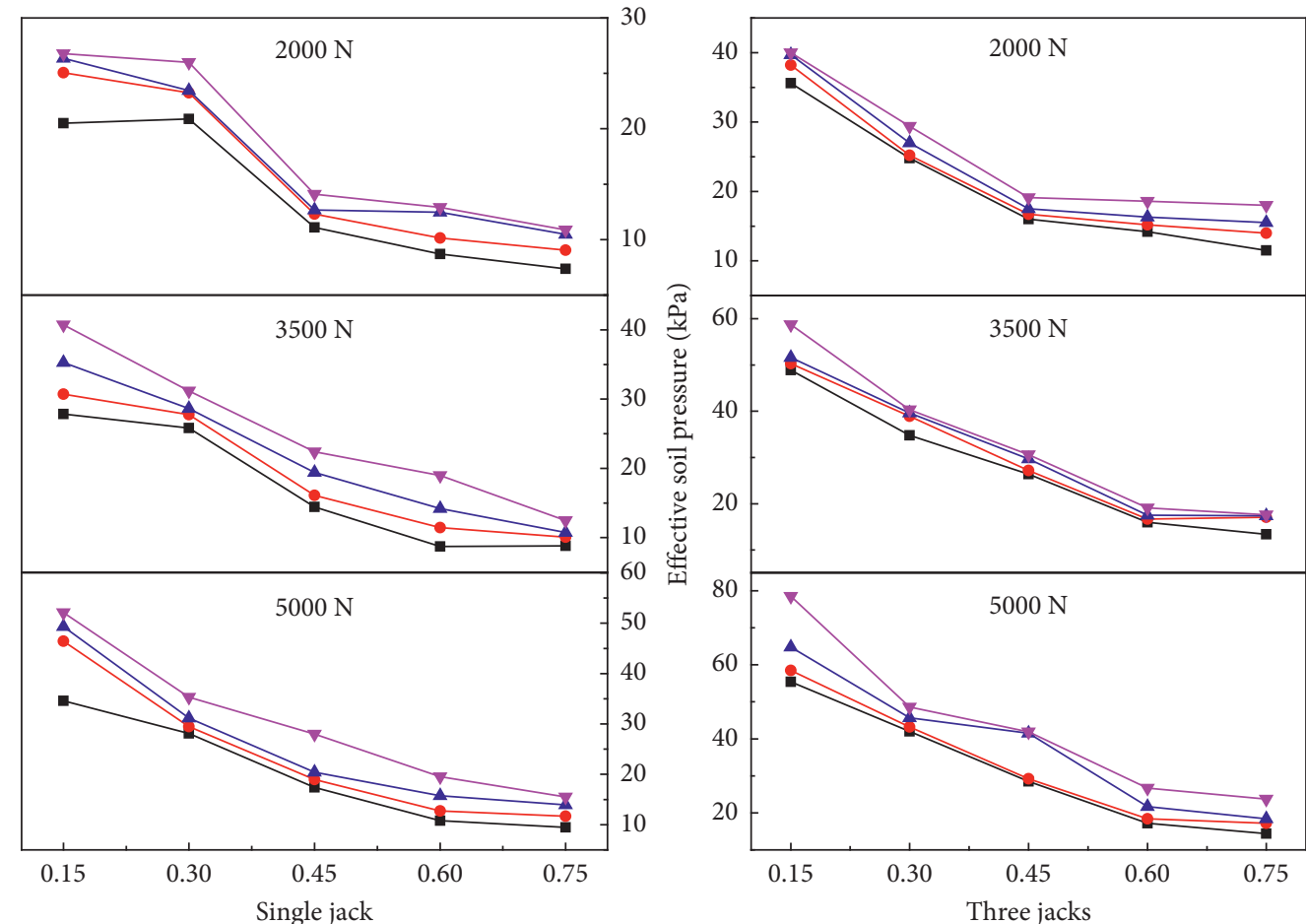

Distance from vibration source, $h(\mathrm{~m})$
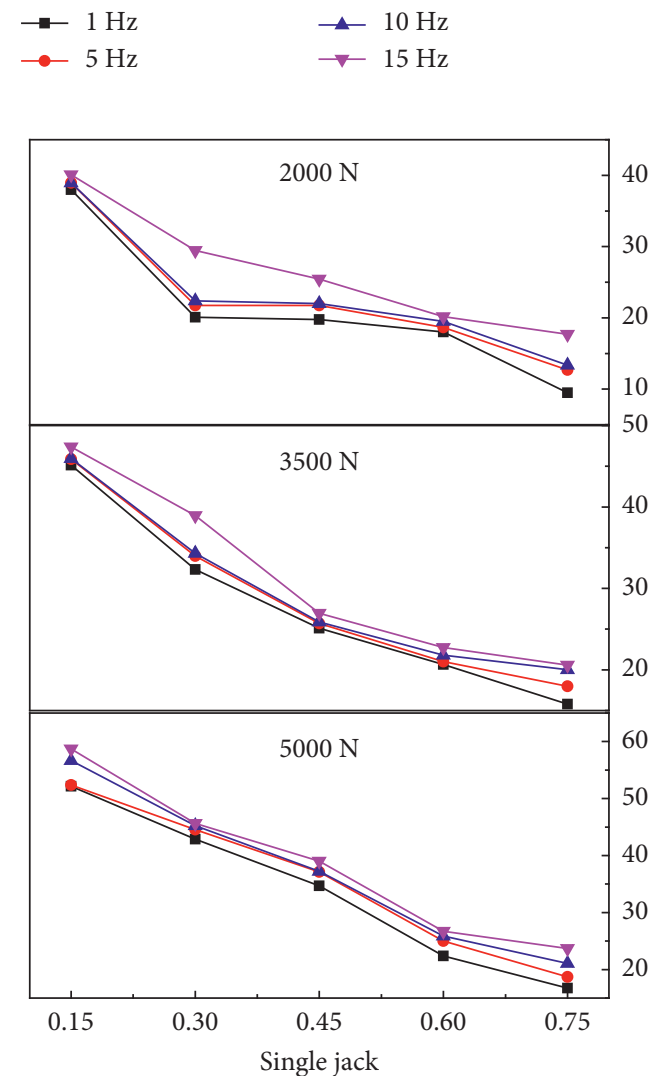

(a)

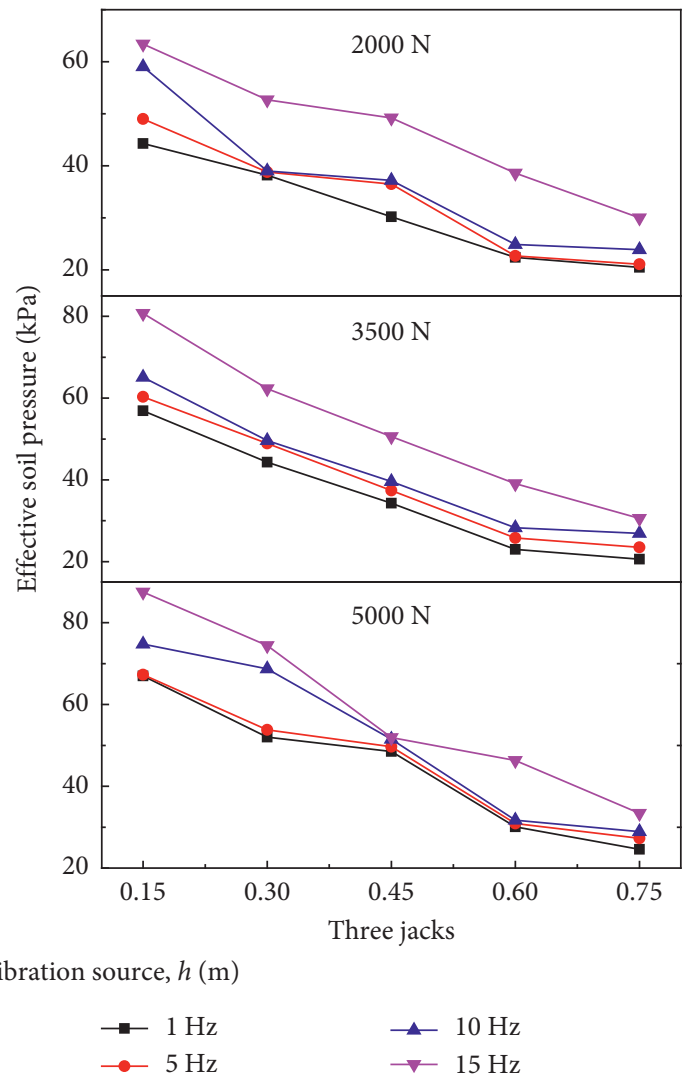

(b)

FIGURE 14: Comparison of the effective soil pressure under different excitation loads under the single jack and three jacks conditions: (a) sand bag and (b) gravel. 
effective soil pressure reaches the maximum value for an excitation frequency of $15 \mathrm{~Hz}$. Further, when the filling materials are changed from sand bag to gravel, the effective soil pressure generally increases. In other words, filling the subgrade with gravel results is a greater vibration response compared to filling with the sand bag.

An empirical formula to obtain the effective soil pressure of the subgrade medium $\delta_{\mathrm{B}}$ can be expressed as follows [36]:

$$
\delta_{\mathrm{B}}=1.33-\frac{g}{1+j h^{3.4}},
$$

where $g$ and $j$ are two parameters.

An alternative empirical approach to calculate the effective soil pressure of the subgrade medium $\delta_{\mathrm{D}}$ can be written as follows [37]:

$$
\delta_{\mathrm{D}}=\left(a_{1}-a_{2} h\right) \frac{P_{0}}{b_{0} l_{0}} \frac{2 H_{0}}{1000\left(2 b_{0} k_{\mathrm{p}}+H_{0} k_{\mathrm{p}}-2 H_{0}\right) l_{0}},
$$

where $H_{0}$ is the height of the subgrade medium; the length of the plate $b_{0}=l_{0}=0.8 \mathrm{~m} ; k_{\mathrm{p}}$ is the effective soil pressure constant $\left(k_{\mathrm{p}}=1+\sin \theta / 1-\sin \theta\right.$, where $\theta$ is the internal friction angle of the subgrade medium); and $a_{1}$ and $a_{2}$ are two parameters.

Figures 15 and 16 compare the measured effective soil pressures with those obtained using the empirical formulae for a subgrade with different filling media in the case of single jack. Most of the test data not only have a certain nonlinear relationship with equation (22) but also have a certain linear relationship with equation (23). Moreover, the relative error between most of the measured data and the two empirical formulae is low.

To further verify the relationship between the test data and empirical formulae, the analysis is performed using three jacks, as shown in Figures 17 and 18. The results have a strong consistency. In other words, the empirical formulae (22) and (23) can be used to effectively describe the dynamic response of the subgrade in this experiment.

The effective soil pressures of the central and slope areas are generally tested under four conditions: sand bag-single jack, sand bag-three jacks, gravel-single jack, and gravelthree jacks, as shown in Figure $19(P=5000 \mathrm{~N}, f=10 \mathrm{~Hz})$. The effective soil pressure and attenuation rates are compared under the four conditions. It is found that the attenuation rate of the same filling medium in the horizontal direction under the single jack condition is generally higher than that under the three jacks condition. Moreover, the effective soil pressure of the central area is generally higher than that of the slope area. This result is observed mainly because the load effect in the slope area is smaller than that in the central area. In addition, the load effect gradually weakens as the distance from the vibration source increases.

4.3. Acceleration. Figures 20 and 21 compare the measured peak accelerations under excitations in the cases of single jack and three jacks, respectively, for subgrades filled with sand bag and gravel. The figures show that the peak acceleration increases significantly with the increase in the excitation load, particularly for the excitation when three

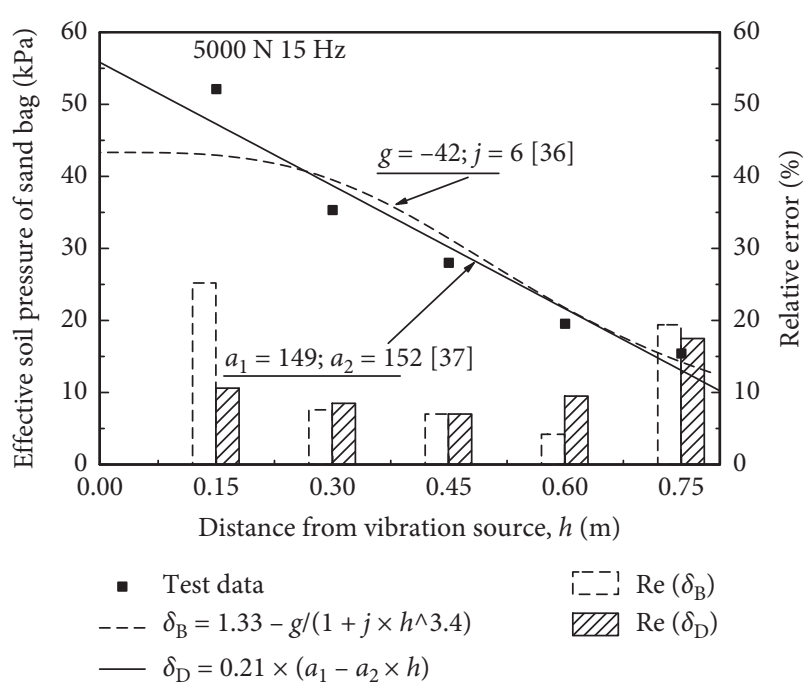

FIGURE 15: Test results and empirical formulae at different measurement points in the case of a single jack (sand bag).

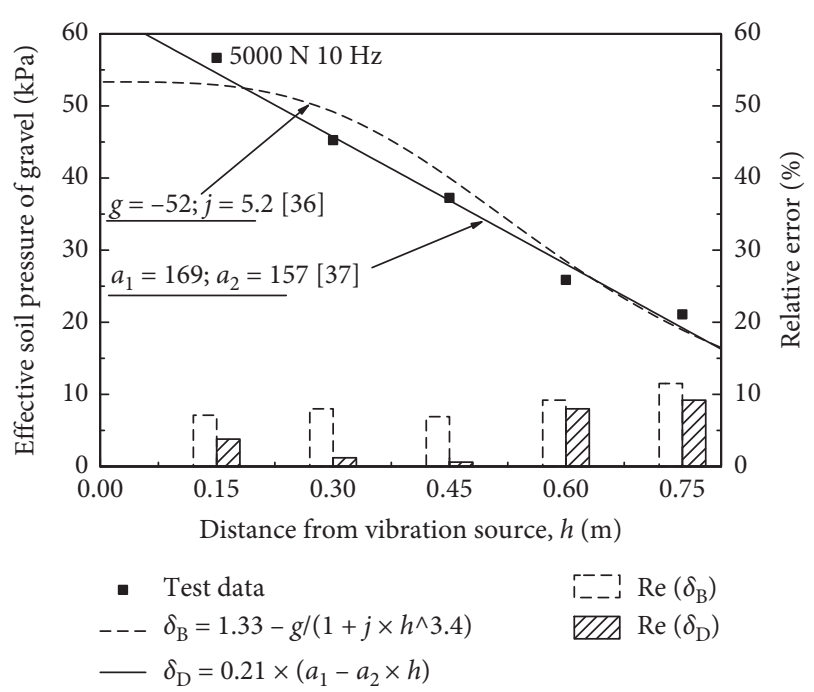

FIgURE 16: Test results and empirical formulae at different measurement points in the case of a single jack (gravel).

jacks are used. In addition, there is an obvious increase in the peak acceleration with the increase in the excitation frequency when the peak acceleration reaches the maximum value for an excitation frequency of $15 \mathrm{~Hz}$. Taking three jacks as an example, when the filling medium changes from sand bag to gravel, the peak acceleration $a_{0.15}$ under $P=5000 \mathrm{~N}$ and $f=10 \mathrm{~Hz}$ changes from $2.31 \mathrm{~m} / \mathrm{s}^{2}$ to $2.15 \mathrm{~m} / \mathrm{s}^{2}$. In other words, the subgrade filled with gravel has a greater vibration reduction effect than that filled with sand bag.

Taking the single jack as an example, Figure 22(a) shows that the peak acceleration of the subgrade has a certain linear relationship with the distance from the vibration source $(P=3500 \mathrm{~N}, f=5 \mathrm{~Hz})$. The fitting linear function can be expressed as follows:

$$
y=y_{0}+\lambda h,
$$




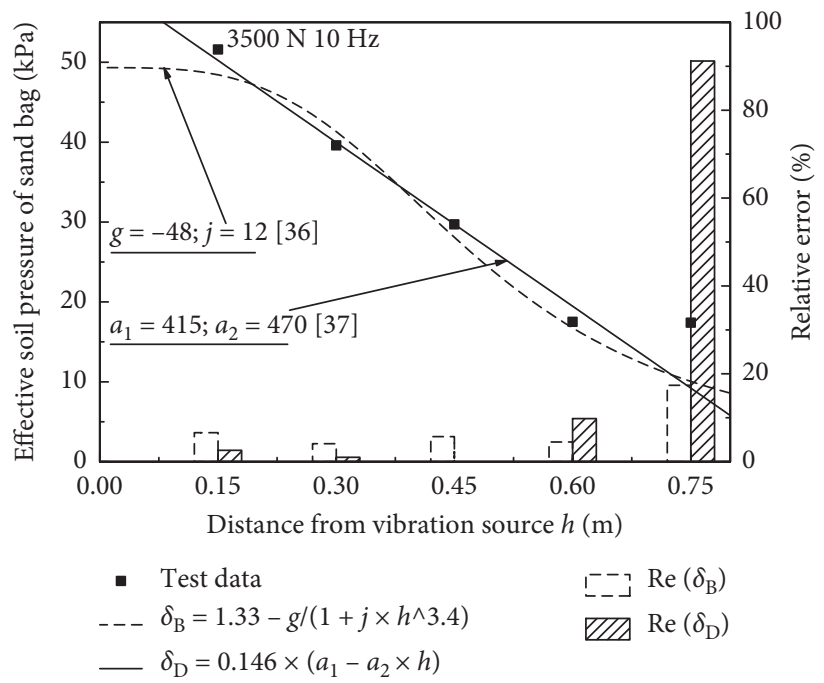

Figure 17: Test results and empirical formulae at different measurement points in the case of three jacks (sand bag).

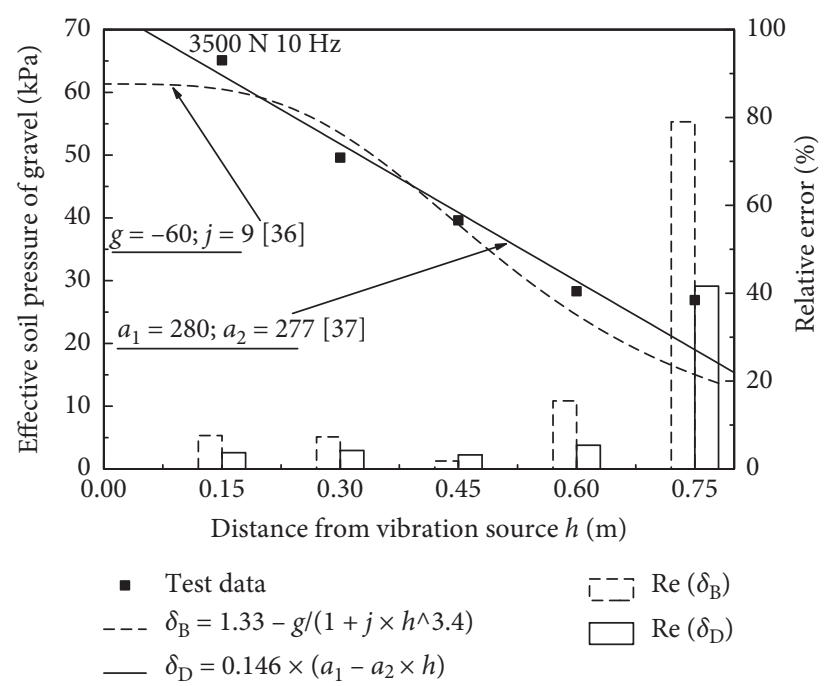

Figure 18: Test results and empirical formulae at different measurement points in the case of three jacks (gravel).

where $y_{0}$ is a coefficient related to the excitation frequency, excitation load, subgrade filling medium, and the number of jacks; $\lambda$ represents the attenuation rate; and $h$ is the distance from the vibration source. Table 7 lists the values of $y_{0}$ and $\lambda$. Although the subgrade filled with gravel has a greater vibration reduction effect than that filled with sand bag, the attenuation rate of the latter is apparently higher than that of the former. In addition, it can be seen from the relative error that there is a strong agreement between the fitting formula and the test data. To further verify the above conclusions, the analysis is performed under the three jacks condition, as shown in Figure 22(b). The results show that equation (24) can be used to fit the acceleration under the three jacks condition.

\section{Conclusions}

The dynamic behavior of a road on subgrades filled with sand bag and gravel is investigated through theoretical derivation and a series of laboratory experiments. The effects of factors, such as the excitation load, excitation frequency, and number of jacks, on the settlement and vibration are analysed. Based on the findings of this study, the following conclusions can be drawn:

(1) Based on the double-layer plate model on the viscoelastic subgrade, an indoor traffic load model system was used to study the dynamic responses of subgrade filled with sand bag and gravel. Gravel as a subgrade filling material was found to have a better vibration reduction effect than sand bag.

(2) The effect of the transfer path on the rigidity of the structural layer was analysed, and the theoretical calculation results were in good agreement with the test data. In other words, the proposed load diffusion model was more accurately verified via experiments. 

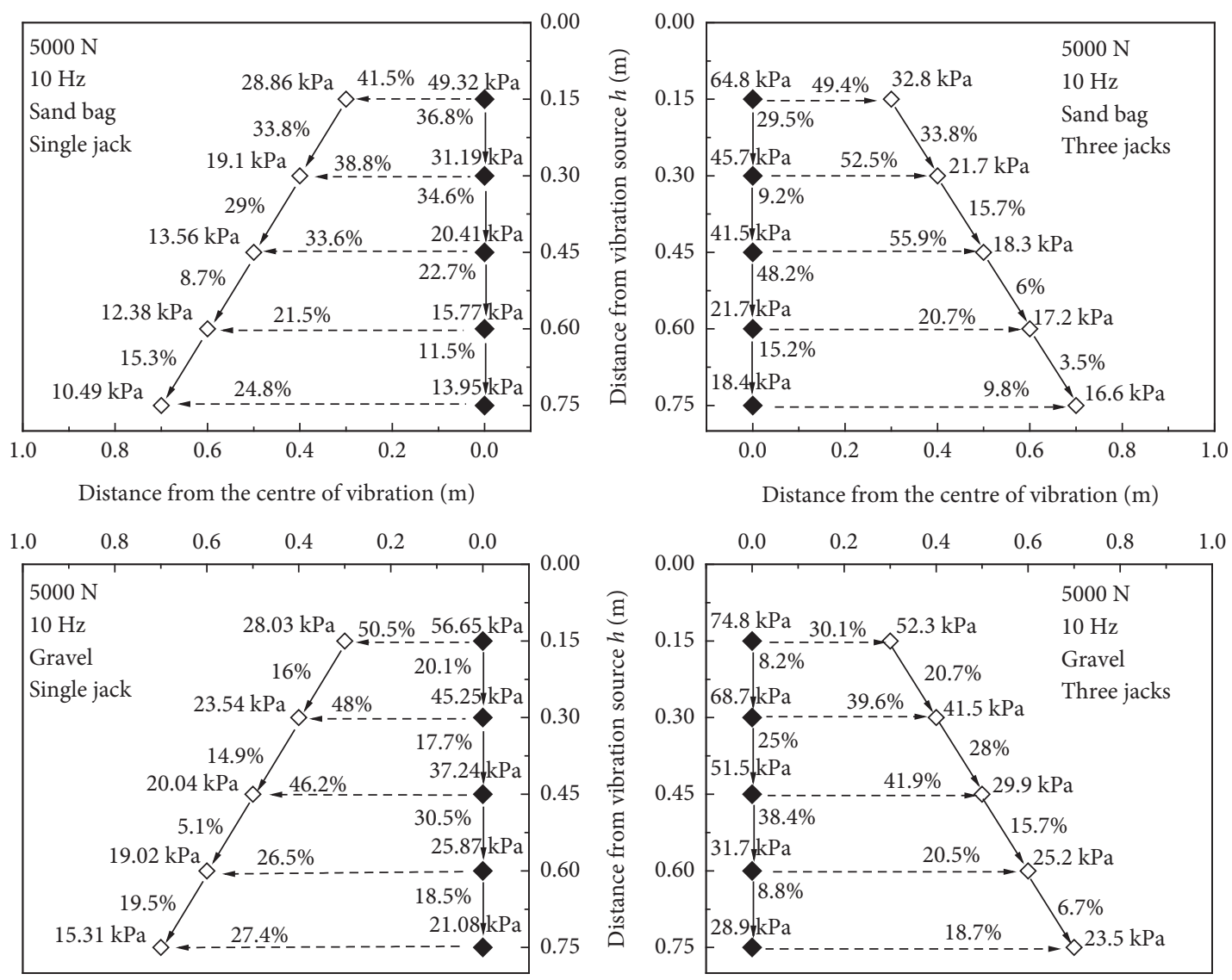

FIgURE 19: Effective soil pressure of the central and slope areas under different conditions.

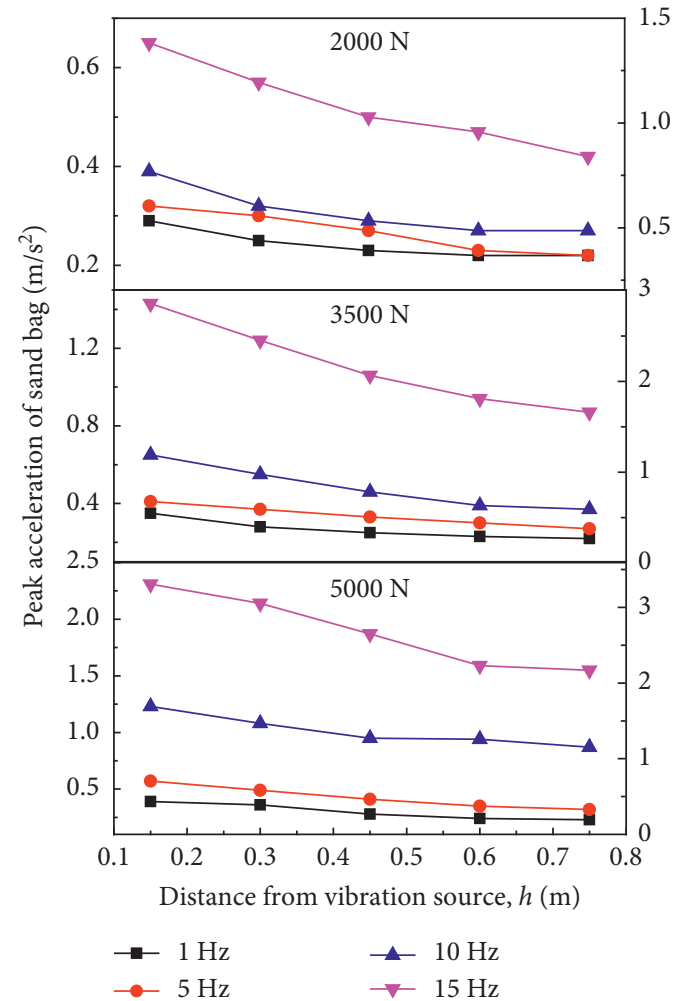

(a)

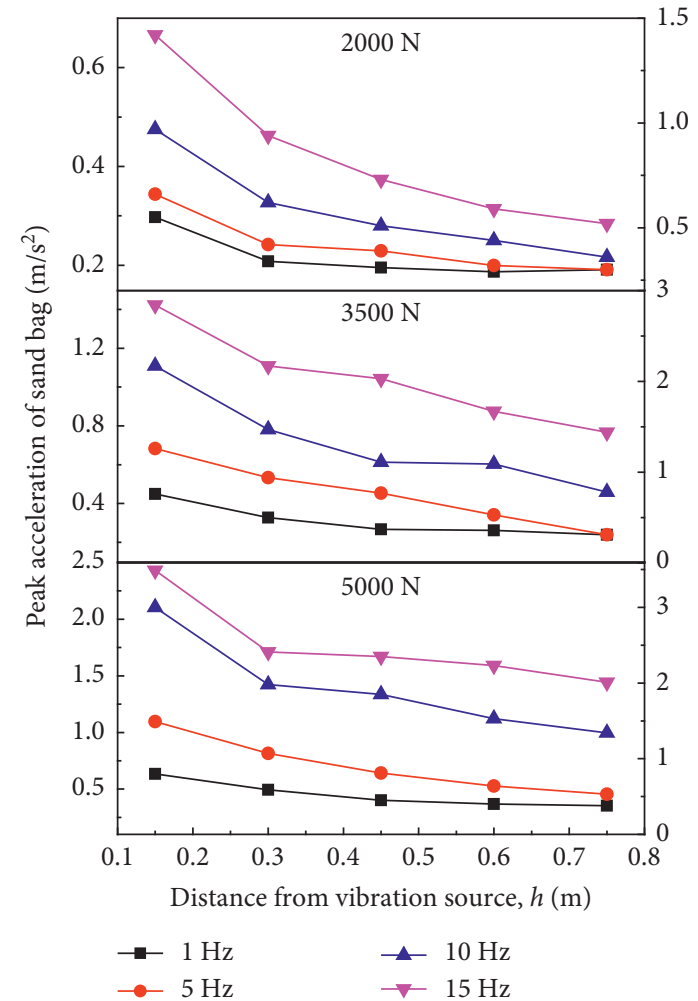

(b)

Figure 20: Peak acceleration for subgrade filled with sand bag under (a) single jack and (b) three jacks. 


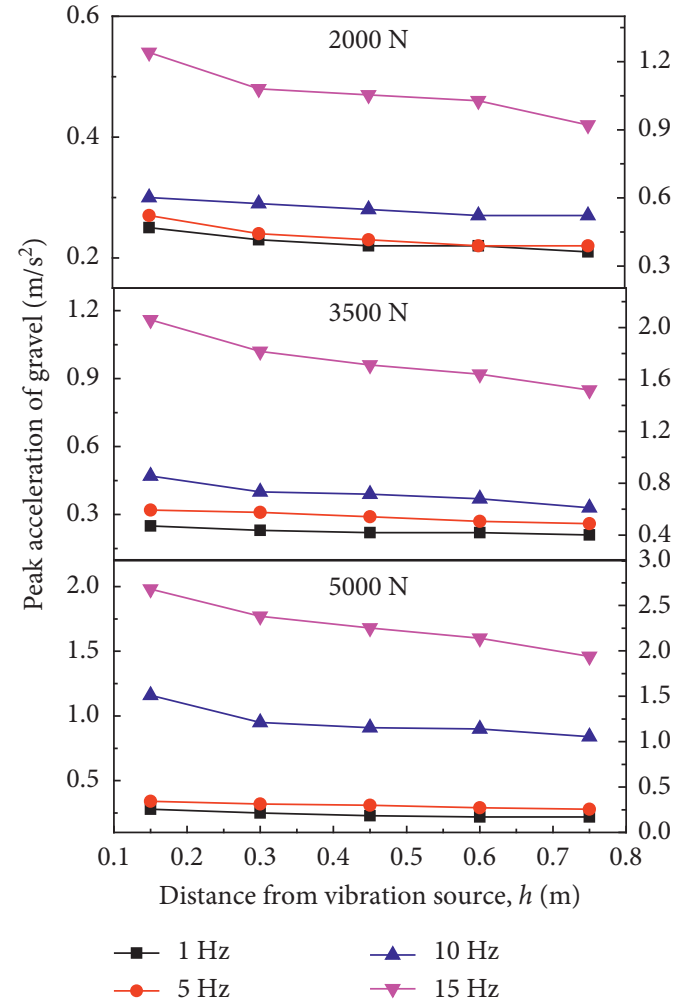

(a)

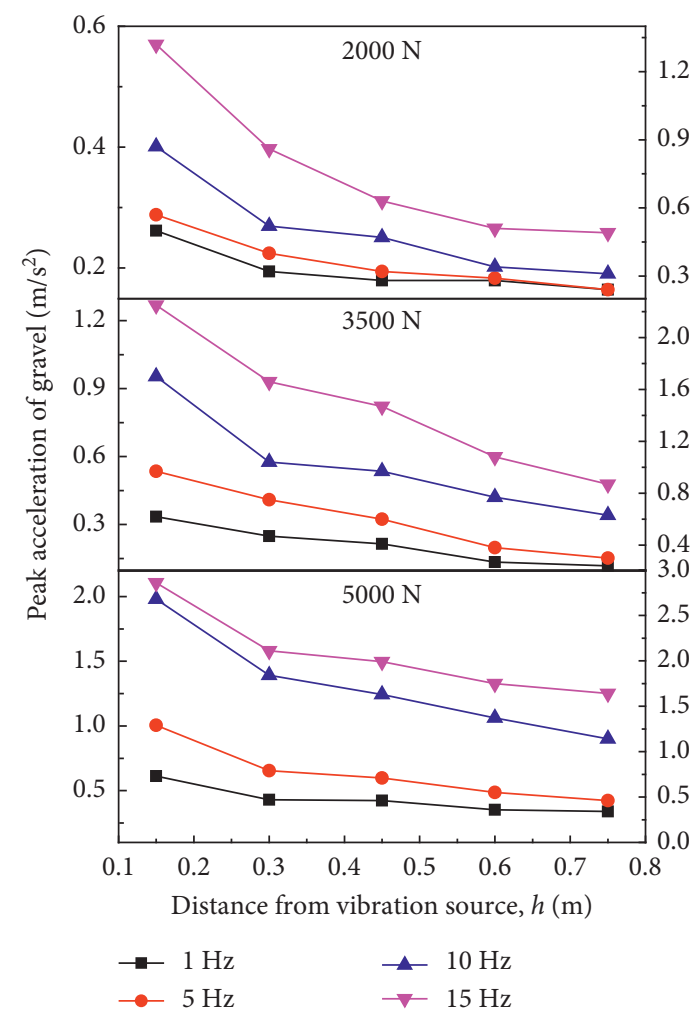

(b)

FIgURe 21: Peak acceleration for subgrade filled with gravel under (a) single jack and (b) three jacks.

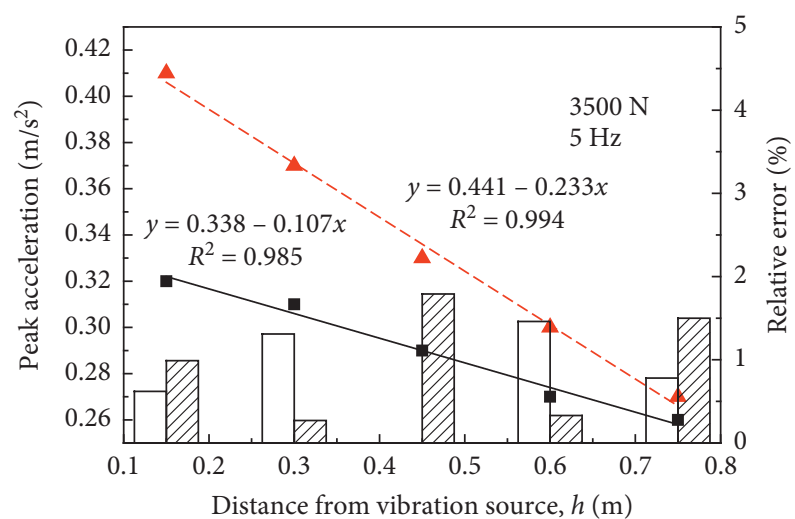

- Test data (gravel)

--- Simulation curve (sand bag)

- Test data (sand bag) $\square \operatorname{Re}$ (gravel)

— Simulation curve (gravel) $\square \Delta \operatorname{Re}($ sand bag)

(a)

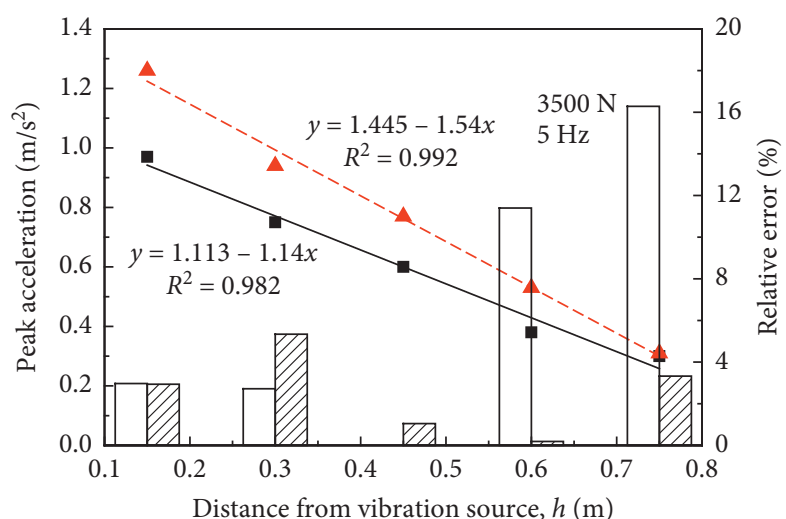

- Test data (gravel) --- Simulation curve (sand bag)

- Test data (sand bag) $\square \operatorname{Re}$ (gravel) — Simulation curve (gravel) DIA Re (sand bag)

(b)

Figure 22: Acceleration test results and fitting formulae: (a) single jack and (b) three jacks.

Table 7: Values of the fitting parameters under different conditions shown in Figure 22.

\begin{tabular}{|c|c|c|c|c|}
\hline Filling medium in subgrade & Number of jacks, $n$ & $y_{0}$ & $\lambda$ & $R^{2}$ \\
\hline \multirow{2}{*}{ Sand bag } & 1 & 0.441 & -0.233 & 0.994 \\
\hline & 3 & 1.121 & -1.127 & 0.986 \\
\hline \multirow{2}{*}{ Gravel } & 1 & 0.338 & -0.107 & 0.985 \\
\hline & 3 & 0.891 & -0.82 & 0.990 \\
\hline
\end{tabular}


(3) The dynamic response of the road increased with an increase in the excitation load and frequency. It is also worth noting that the dynamic response obtained under the three jacks condition cannot be estimated simply by multiplying the parameters associated with the single jack by three times.

\section{Data Availability}

The authors work with a reputable foundation processing unit, so these data are available upon request.

\section{Conflicts of Interest}

The authors declare that they have no conflicts of interest.

\section{Acknowledgments}

This work was supported by the National Key Research and Development Program of China (Grant no. 2016YFC0800200); the Natural Foundation Project of Zhejiang Province (Grant no. LY18E080027); the National Natural Science Foundation of China (Grant nos. 51578425 and 51778501), and the Key Research and Development Program of Zhejiang Province (Grant no. 2018C03038).

\section{References}

[1] J. Oscarsson and T. Dahlberg, "Dynamic train/track/ballast interaction-computer models and full-scale experiments," Vehicle System Dynamics, vol. 29, no. 1, pp. 73-84, 1998.

[2] G. Kouroussis, G. Gazetas, I. Anastasopoulos, C. Conti, and O. Verlinden, "Discrete modelling of vertical track-soil coupling for vehicle-track dynamics," Soil Dynamics and Earthquake Engineering, vol. 31, no. 12, pp. 1711-1723, 2011.

[3] W. Zhai and Z. Cai, "Dynamic interaction between a lumped mass vehicle and a discretely supported continuous rail track," Computers \& Structures, vol. 63, no. 5, pp. 987-997, 1997.

[4] Z. Lu, H. L. Yao, W. P. Wu, and P. Cheng, "Dynamic stress and deformation of a layered road structure under vehicle traffic loads: experimental measurements and numerical calculations," Soil Dynamics and Earthquake Engineering, vol. 39, pp. 100-112, 2012.

[5] S.-S. Lih and A. K. Mal, "On the accuracy of approximate plate theories for wave field calculations in composite laminates," Wave Motion, vol. 21, no. 1, pp. 17-34, 1995.

[6] X. Sheng, C. J. C. Jones, and M. Petyt, "Ground vibration generated by a load moving along a railway track," Journal of Sound and Vibration, vol. 228, no. 1, pp. 129-156, 1999.

[7] X. Sheng and C. J. C. Jones, D. J. Thompson, A theoretical model for ground vibration from trains generated by vertical track irregularities," Journal of Sound and Vibration, vol. 272, no. 3-5, pp. 937-965, 2006.

[8] A. Karlström and A. Boström, "An analytical model for traininduced ground vibrations from railways," Journal of Sound and Vibration, vol. 292, no. 1-2, pp. 221-241, 2006.

[9] A. Karlström, "An analytical model for ground vibrations from accelerating trains," Journal of Sound and Vibration, vol. 293, no. 3-5, pp. 587-598, 2006.

[10] R. M. Mulungye, P. M. O. Owende, and K. Mellon, "Finite element modelling of flexible pavements on soft soil subgrades," Materials \& Design, vol. 28, no. 3, pp. 739-756, 2007.
[11] M. Kim and E. Tutumluer, "Validation of a three-dimensional finite element model using airfield pavement multiple wheel load responses," Road Materials and Pavement Design, vol. 11, no. 2, pp. 387-408, 2010.

[12] D. Younesian and M. Sadri, "Effects of the trench geometry on vibration mitigation level in high-speed railway tracks," Journal of Mechanical Science and Technology, vol. 26, no. 8, pp. 2469-2476, 2012.

[13] D. Connolly, A. Giannopoulos, and M. C. Forde, "Numerical modelling of ground borne vibrations from high speed rail lines on embankments," Soil Dynamics and Earthquake Engineering, vol. 46, pp. 13-19, 2013.

[14] C. G. Koh, J. S. Y. Ong, D. K. H. Chua, and J. Feng, "Moving element method for train-track dynamics," International Journal for Numerical Methods in Engineering, vol. 56, no. 11, pp. 1549-1567, 2003.

[15] K. M. Rasmussen, S. R. K. Nielsen, and P. H. Kirkegaard, "Boundary element method solution in the time domain for a moving time-dependent force," Computers \& Structures, vol. 79, no. 7, pp. 691-701, 2001.

[16] S.-M. Kim and J. M. Roesset, "Moving loads on a plate on elastic foundation," Journal of Engineering Mechanics, vol. 124, no. 9, pp. 1010-1017, 1998.

[17] S.-M. Kim and B. F. McCullough, "Dynamic response of plate on viscous Winkler foundation to moving loads of varying amplitude," Engineering Structures, vol. 25, no. 9, pp. 11791188, 2003.

[18] S.-M. Kim, "Influence of horizontal resistance at plate bottom on vibration of plates on elastic foundation under moving loads," Engineering Structures, vol. 26, no. 4, pp. 519-529, 2004.

[19] L. Sun, "A closed-form solution of beam on viscoelastic subgrade subjected to moving loads," Computers \& Structures, vol. 80, no. 1, pp. 1-8, 2002.

[20] L. Sun, "Dynamic response of Kirchhoff plate on a viscoelastic foundation to harmonic circular loads," Journal of Applied Mechanics, vol. 70, no. 4, pp. 595-600, 2003.

[21] L. Sun, "Dynamics of plate generated by moving harmonic loads," Journal of Applied Mechanics, vol. 72, no. 5, pp. 772-777, 2005.

[22] M. H. Kargarnovin and D. Younesian, "Dynamics of Timoshenko beams on Pasternak foundation under moving load," Mechanics Research Communications, vol. 31, no. 6, pp. 713-723, 2004.

[23] M. H. Kargarnovin, D. Younesian, D. J. Thompson, and C. J. C. Jones, "Response of beams on nonlinear viscoelastic foundations to harmonic moving loads," Computers \& Structures, vol. 83, no. 23-24, pp. 1865-1877, 2005.

[24] M.-H. Huang and D. P. Thambiratnam, "Dynamic response of plates on elastic foundation to moving loads," Journal of Engineering Mechanics, vol. 128, no. 9, pp. 1016-1022, 2002.

[25] M.-H. Huang and D. P. Thambiratnam, "Deflection response of plate on Winkler foundation to moving accelerated loads," Engineering Structures, vol. 23, no. 9, pp. 1134-1141, 2001.

[26] Z. Lu, H. L. Yao, H. N. Luo, and Y. Yang, "Parameter analysis of continuously reinforced concrete pavement resting on twoparameter foundation," Rock and Soil Mechanics, vol. 29, no. 8, pp. 2177-2182, 2008.

[27] Z. Lu and H. L. Yao, "Effects of the dynamic vehicle-road interaction on the pavement vibration due to road traffic," Journal of Vibroengineering, vol. 15, no. 3, pp. 1291-1301, 2013.

[28] H. S. Zibdeh and M. Abu-Hilal, "Stochastic vibration of laminated composite coated beam traversed by a random 
moving load," Engineering Structures, vol. 25, no. 3, pp. 397-404, 2003.

[29] S. Nimbalkar and B. Indraratna, "Improved performance of ballasted rail track using geosynthetics and rubber shockmat," Journal of Geotechnical and Geoenvironmental Engineering, vol. 142, no. 8, article 04016031, 2016.

[30] S.-H. Liu, J.-J. Gao, Y.-Q. Wang, and L.-P. Weng, "Experimental study on vibration reduction by using soilbags," Geotextiles and Geomembranes, vol. 42, no. 1, pp. 52-62, 2014.

[31] A. A. Shaer, D. Duhamel, K. Sab, G. Foret, and L. Schmitt, "Experimental settlement and dynamic behavior of a portion of ballasted railway track under high speed trains," Journal of Sound and Vibration, vol. 316, no. 1-5, pp. 211-233, 2008.

[32] Z. Zhang, H. Xiang, and Z. Shi, "Modeling on piezoelectric energy harvesting from pavements under traffic loads," Journal of Intelligent Material Systems and Structures, vol. 27, no. 4, pp. 567-578, 2016.

[33] C. Liu, B. F. McCullough, and H. S. Oey, "Response of rigid pavements due to vehicle-road interaction," Journal of Transportation Engineering, vol. 126, no. 3, pp. 237-242, 2000.

[34] W. M. Zhai, K. Y. Wang, and J. H. Lin, "Modelling and experiment of railway ballast vibrations," Journal of Sound and Vibration, vol. 270, no. 4-5, pp. 673-683, 2004.

[35] B. Indraratna and S. Nimbalkar, "Stress-strain degradation response of railway ballast stabilized with geosynthetics," Journal of Geotechnical and Geoenvironmental Engineering, vol. 139, no. 5, pp. 684-700, 2013.

[36] X. Bian, H. Jiang, C. Cheng, Y. Chen, R. Chen, and J. Jiang, "Full-scale model testing on a ballastless high-speed railway under simulated train moving loads," Soil Dynamics and Earthquake Engineering, vol. 66, pp. 368-384, 2014.

[37] G. Ding, J. Wu, J. Wang, and X. Hu, "Effect of sand bags on vibration reduction in road subgrade," Soil Dynamics and Earthquake Engineering, vol. 100, pp. 529-537, 2017. 


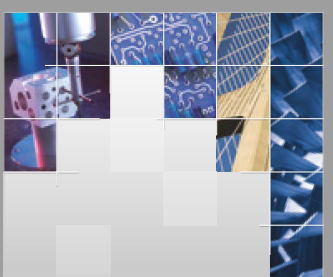

\section{Enfincering}
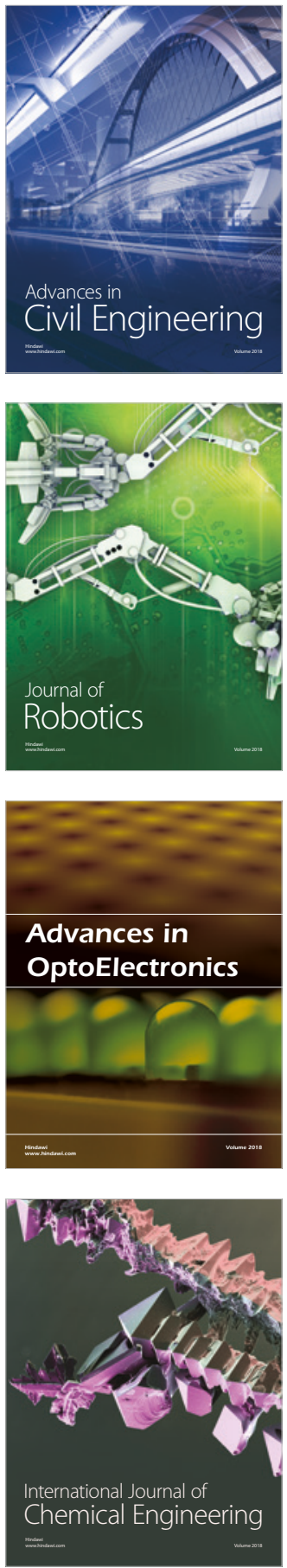

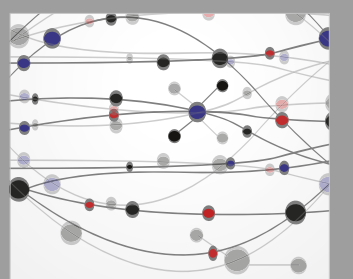

\section{Rotating \\ Machinery}

The Scientific World Journal

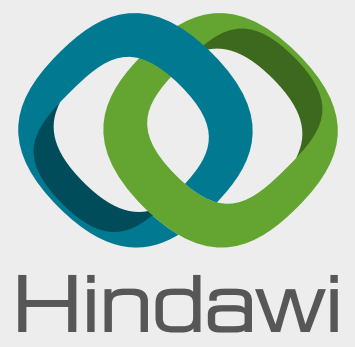

Submit your manuscripts at

www.hindawi.com
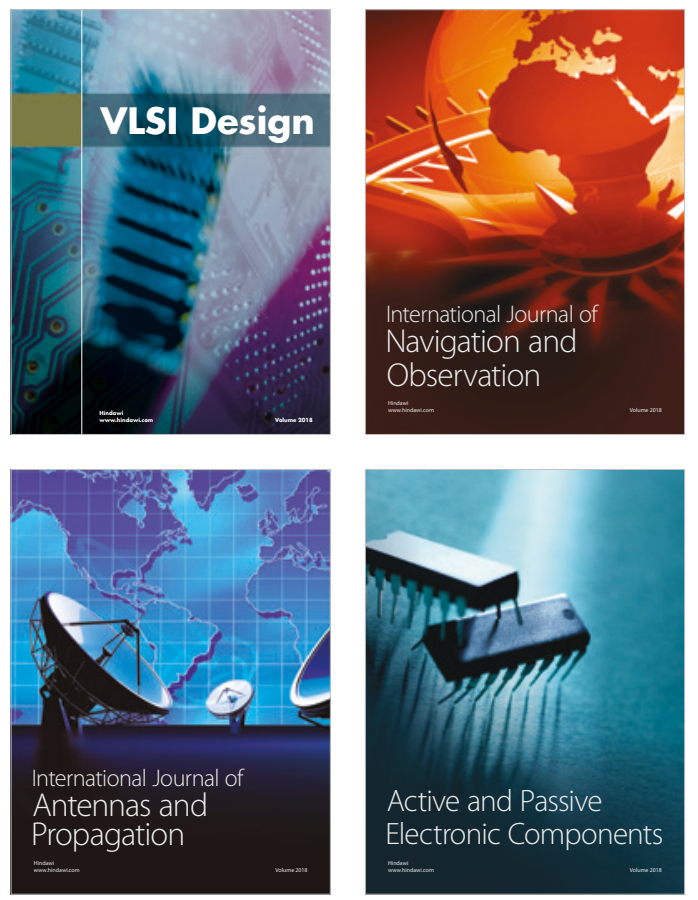
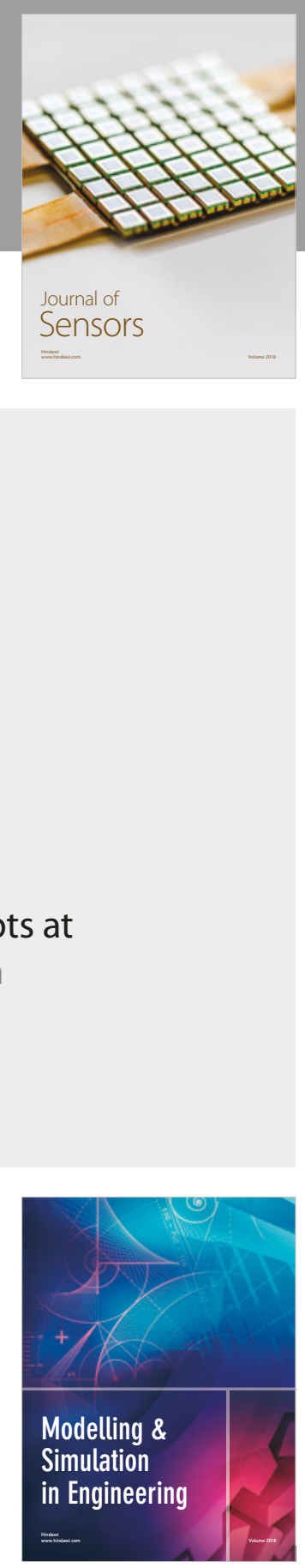

\section{Advances \\ Multimedia}
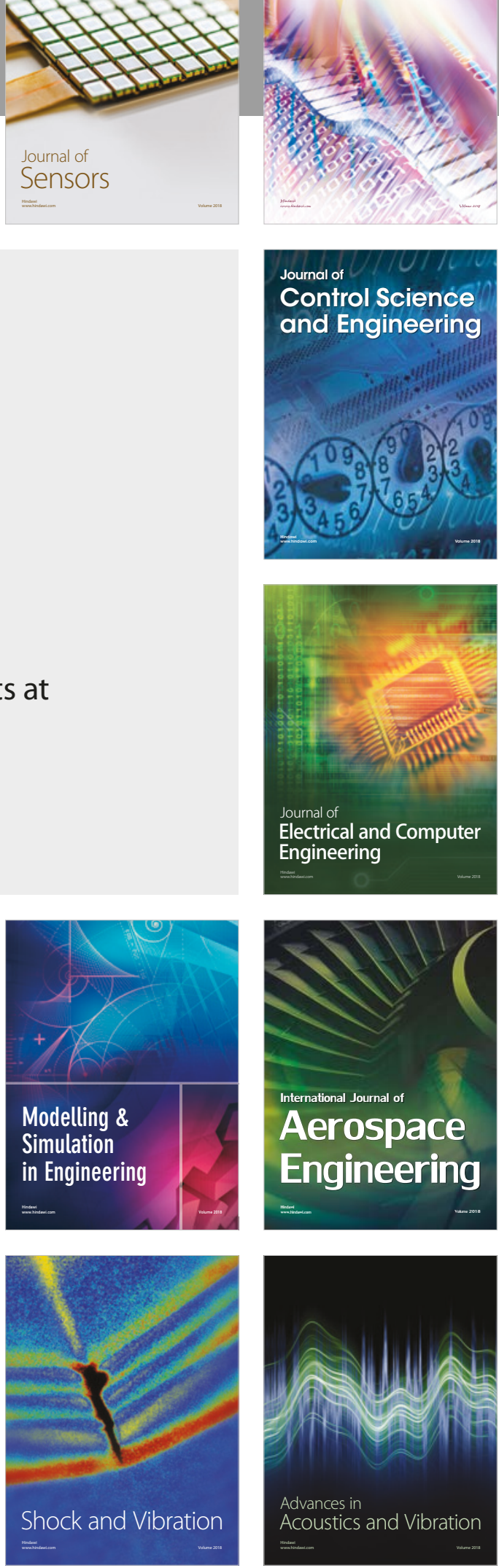